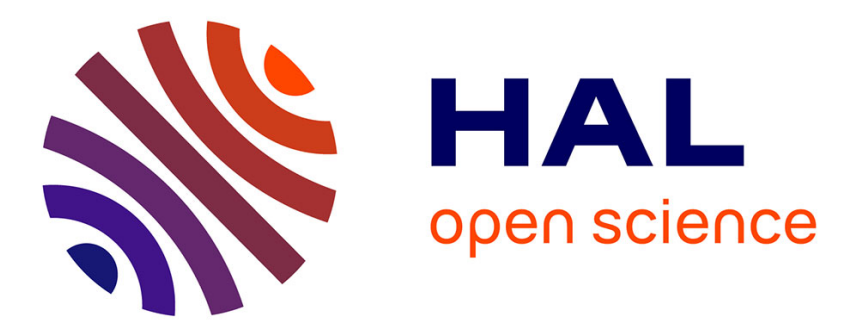

\title{
Condition-based probabilistic safety assessment of a spontaneous steam generator tube rupture accident scenario
}

Francesco Di Maio, Federico Antonello, Enrico Zio

\section{- To cite this version:}

Francesco Di Maio, Federico Antonello, Enrico Zio. Condition-based probabilistic safety assessment of a spontaneous steam generator tube rupture accident scenario. Nuclear Engineering and Design, 2018, 326, pp.41 - 54. 10.1016/j.nucengdes.2017.10.020 . hal-01786565

\section{HAL Id: hal-01786565}

https://hal-centralesupelec.archives-ouvertes.fr/hal-01786565

Submitted on 19 Mar 2020

HAL is a multi-disciplinary open access archive for the deposit and dissemination of scientific research documents, whether they are published or not. The documents may come from teaching and research institutions in France or abroad, or from public or private research centers.
L'archive ouverte pluridisciplinaire HAL, est destinée au dépôt et à la diffusion de documents scientifiques de niveau recherche, publiés ou non, émanant des établissements d'enseignement et de recherche français ou étrangers, des laboratoires publics ou privés. 


\title{
Condition-Based Probabilistic Safety Assessment of a Spontaneous Steam Generator Tube Rupture Accident Scenario
}

\author{
Francesco Di Maio', Federico Antonello ${ }^{1}$, Enrico Zio ${ }^{1,2}$ \\ ${ }^{1}$ Energy Department, Politecnico di Milano, Via La Masa 34, 20156 Milano, Italy

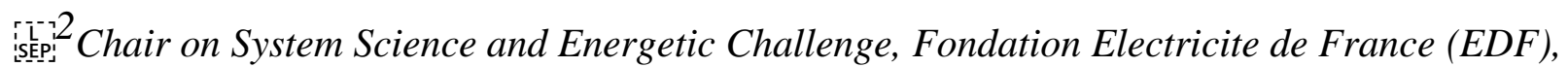 \\ CentraleSupelec, Université Paris Saclay, Grande Voie des Vignes, 92290 Châtenay-Malabry, \\ France
}

\begin{abstract}
Condition-Based Probabilistic Safety Assessment (CB-PSA) makes use of the information made available during operation by sensors and/or inspections on the state of components and systems. This allows specializing the PSA to the conditions of the components and systems, reducing the uncertainty on the risk measures quantified.

In this paper, we demonstrate the CB-PSA with reference to a spontaneous Steam Generator Tube Rupture (SGTR) accident scenario in a Pressurized Water Reactor (PWR). Results show that the updated risk measures are capable of reflecting the actual state of the SG in the tailored risk evaluation.
\end{abstract}

Keywords: Probabilistic Safety Assessment (PSA), Living PSA (LPSA), Condition-based PSA (CBPSA), Steam Generator (SG), SG tube rupture (SGTR). 


\section{INTRODUCTION}

Probabilistic Safety Assessment (PSA) is a framework that systematizes the available knowledge for analysing design and operational vulnerabilities of complex systems and quantifying the related risk measures (IAEA-TECDOC-737 1994)(IAEA-TECDOC-1106 1999) (R. Nakai \&Y. Kani. 1991). In Nuclear Power Plants (NPPs) these are, for example, Core Damage Frequency (CDF) and Large Early Release Frequency (LERF) (IAEA, 2006) (M. Zubair et. al. 2011). PSA involves system accident analysis by techniques like Event Tree Analysis (ETA) and Fault Tree Analyses (FTA) to define accident sequences and calculate the frequency of the system end states (for example, Core Damage) reached along the accident scenarios.

As knowledge on the components states changes during the system life, PSA results need to be updated by embedding failure data, physical knowledge and monitored data on the conditions of the components. For example, in the Living PSA (LPSA) paradigm the PSA is updated to reflect plant changes and embed field failure data (IAEA-TECDOC-1106 1999). LPSA is a plant specific PSA that can be updated or modified to reflect the plant changes during the lifetime (G. Johanson \& J. Holmberg. 1994). Changes can be physical (resulting from plant modifications, etc.), operational (resulting from enhanced procedures, etc.), organizational, but can be also changes in knowledge due to the acquisition of operational experience, field failure data, etc. The updated LPSA, then, reflects the current design and operational state of the system, and is documented in a way that each aspect of the model can be directly related to existing plant information, plant documentation or analysts assumption (IAEA-TECDOC$1106,1999)$.

In this paper, we extend and advance LPSA by proposing a Condition-Based PSA (CB-PSA) framework. This novel concept is here presented for the first time, extending the capability of LPSA by incorporating knowledge on the state of the components, as estimated from monitored data. The development and renovation of Non-Destructive Examination (NDE) technology has also improved the quantity and quality of the available data (L. Obrutsky et. al. 2014), boosting the development of techniques aimed to process those data and information to increase the capability of PSA and LPSA to provide actualized, tailored and robust risk measures. CB-PSA actualizes the risk measures to the current state of the components, based on the information on the components states made available by 
monitoring or inspection. This entails integrating PSA techniques like ETA and FTA with condition monitoring techniques (P.V. Varde \& M.G. Pecht. 2015) (IAEA-TECDOC-1106, 1999) (T. Aldemir. 2013) (S. Poghosyan \& A. Amirjanyan. 2015) (H. Kim et. al. 2015) that provide estimates of components states and associated uncertainties, thus reducing conservativism and uncertainty on the risk measured quantified (E. Zio. 2016). The empirical distributions based on field failure data of LPSA are replaced by condition-based distributions obtained by the integration of physics-based knowledge and monitoring data on the ongoing degradation mechanisms and aging phenomena affecting the components, as well on environmental and operational conditions. Figure 1 gives the idea by sketching the failure probability given by conventional PSA (dotted line), the updated failure probability computed by LPSA (continuous line) and the condition-based failure probability provided by CB-PSA (dashed line). Conventional PSA estimates the failure probability based on the knowledge and information available before operation, neglecting future time-dependent variations, e.g. due aging, failure and maintenance; LPSA updates conventional PSA to reflect changes in the plant configuration; CB-PSA uses condition-monitoring data for updating the failure probability at each cycle time.

The remainder of this paper is as follows: in Section 2, the case study of a spontaneous Steam Generator Tube Rupture (SGTR) in a pressurized water reactor (PWR) is considered and the models used to implement the CB-PSA are described. In Section 3, the CB-PSA framework is presented along with a plugging optimization methodology for limiting the occurrences of a spontaneous SGTR accident event. Section 4 draws some conclusions. 


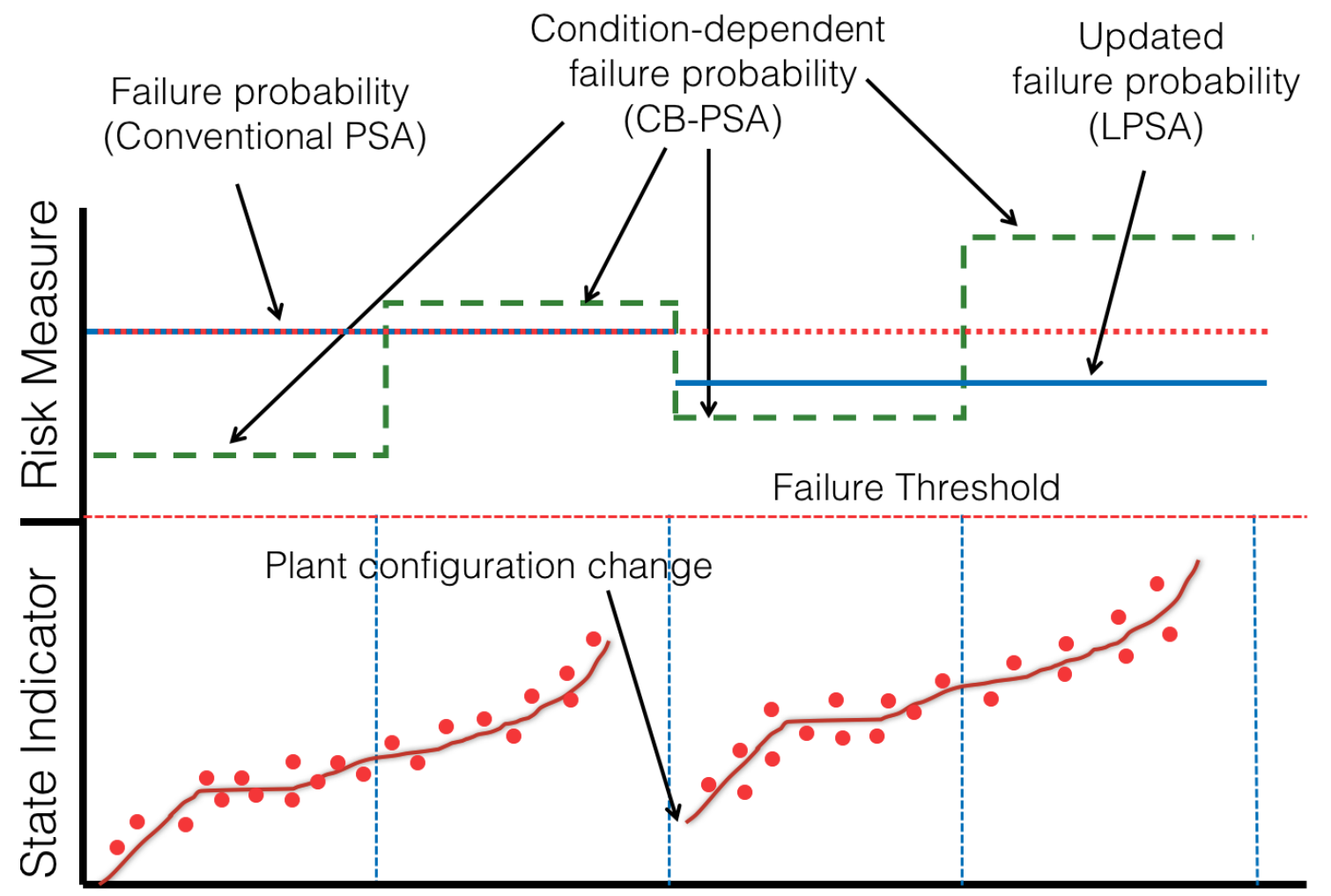

\section{CYCLES}

Figure 1. Comparison between failure probability provided by conventional PSA and condition-based failure probability provided by CB-PSA.

\section{The Spontaneous SGTR accident scenario}

SGTR can be either an induced or a spontaneous phenomenon. An induced SGTR consist in the break of one or more SG tubes that is triggered by other internal events, such as a Steam Line Break (SLB), whereas a spontaneous SGTR is not (NUREG/CR-6365 INEL-95/0383, 1996).

Figure 2 shows the simplified ET that follows to a spontaneous SGTR Initiating Event (IE). The frequencies of the events along the sequences in the ET are estimated from statistical analysis of reliability data and expert judgement, if needed (H. Kim et. al. 2015). 


\begin{tabular}{|c|c|c|c|c|}
\hline $\begin{array}{c}\text { Spontaneous } \\
\text { SGTR }\end{array}$ & $\begin{array}{c}\text { Operator } \\
\text { Depressurization }\end{array}$ & $\begin{array}{c}\text { Refuelling Water } \\
\text { Storage Tank }\end{array}$ & $\begin{array}{c}\text { Reactor Coolant } \\
\text { System }\end{array}$ & End State \\
\cline { 1 - 4 } IE & OD & RWST & RCS & \\
\hline
\end{tabular}

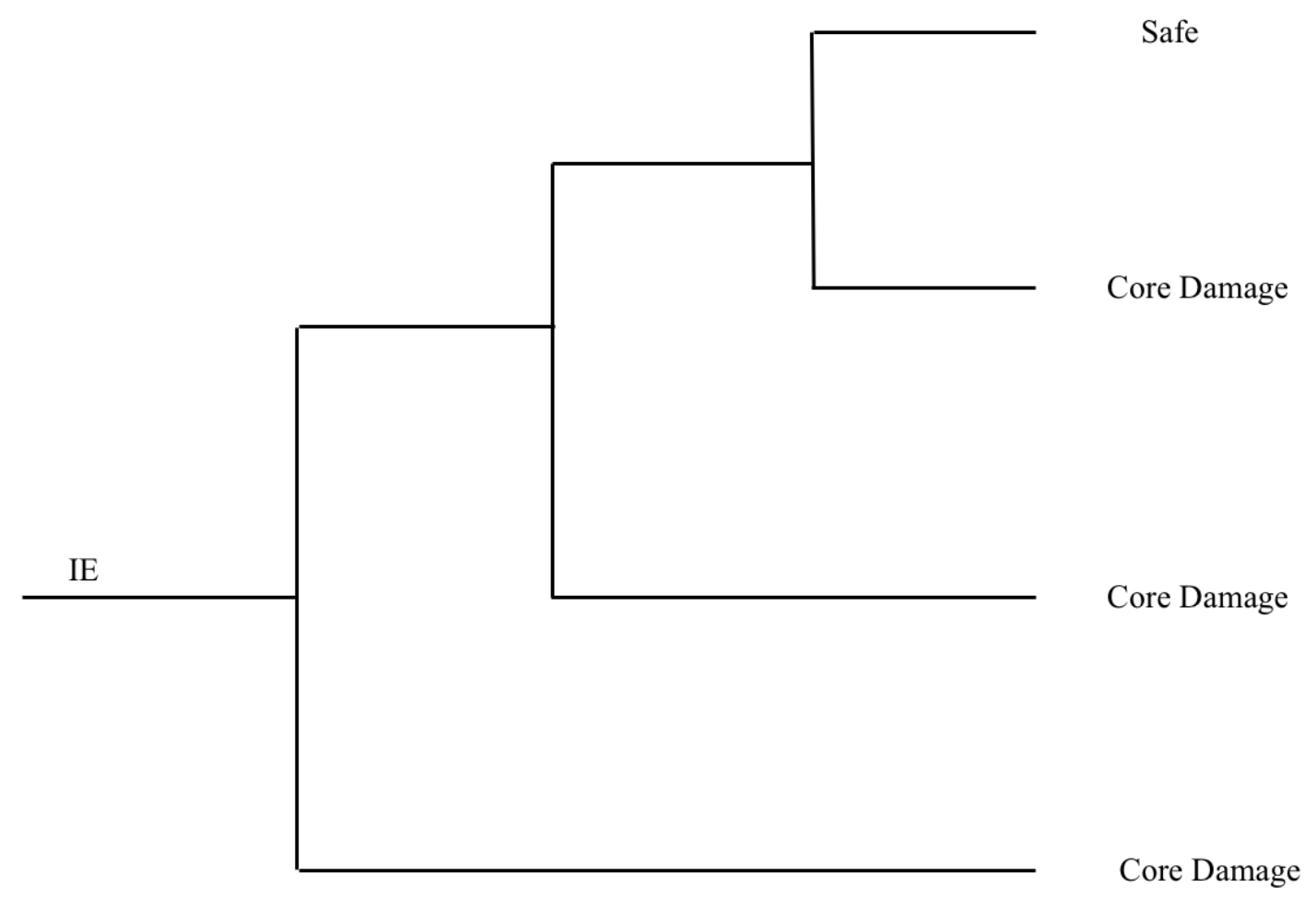

Figure 2. Simplified ET of spontaneous SGTR.

The frequency $f_{S G T R}$ of the spontaneous SGTR IE of Figure 2 (which is used within the conventional PSA, performed for the Safety Assessment Review (SAR) that has to be submitted to the regulatory authority for licensing) is given by Eq. (1):

$$
f_{S G T R}=\frac{N+1 / 2}{T}
$$

where $N$ is the number of SGTR occurrences in $T$ years of similar NPP operations (for example, $N=3$ in $T=499$ years as reported in (M.B. Sattison \& K.W. Hall. 1989), resulting in $f_{\text {SGTR }}=7.0 \mathrm{E}-03$ per year $(\mathrm{H}$. Kim et. al. 2015)). 
Assuming the failure on demand probability of the operator depressurization $O D$, the failure probability of refill of the storage tank RWST and the failure probability of the reactor safety system $R S C$ equal to 1.8E-4, 2.4E-8, 5.6E-5, respectively (R. Lewandowski, 2013), the CDF is equal to 3.92E-7 per year.

In this work, the spontaneous SGTR is analyzed within a condition-based PSA. A model for the onset, formation and propagation of spontaneous cracks in the SG is used to update the probability of the SGTR IE throughout the system lifetime and the CDF is updated by the analysis of the current state of the plant.

\subsection{The Steam Generator}

LPSA and CB-PSA are plant specific PSA. To show the capability of the proposed CB-PSA approach to follow the specificities of the system under analysis and to tailor its specific operative conditions, we focus on the SG of the Zion PWR NPP, equipped with a recirculating SG of $3.6 \mathrm{~m}$ and $21 \mathrm{~m}$ of diameter and height, respectively, $800 \mathrm{t}$ of weight, a bundle of 3592 inverted $\mathrm{U}$ tubes with an outside diameter of $22.23 \mathrm{~mm}$ and a wall thickness of $1.27 \mathrm{~mm}$ (R. Lewandowski, 2013). The primary loop nominal pressure is $15.2 \mathrm{MPa}$, while the secondary loop nominal pressure is $6.9 \mathrm{MPa}$. The hot leg nominal temperature is $330^{\circ} \mathrm{C}$, while the nominal cold leg temperature is $288^{\circ} \mathrm{C}$. A detailed list of Zion NPP parameters values is given in Table I.

Table I. Parameters of the PWR NPP under consideration (R. Lewandowski et. al. 2016)

\begin{tabular}{|l|l|}
\hline NPP Operating Conditions & \\
\hline Nominal Power $W_{\text {nom }}$ & $1110 \mathrm{MW}_{\mathrm{e}}$ \\
\hline Primary side pressure Pin $_{\text {,nom }}$ & $15.2 \mathrm{MPa}$ \\
\hline Secondary side pressure Pout $_{\text {,nom }}$ & $6.9 \mathrm{MPa}$ \\
\hline SG Parameters & \\
\hline Number of tubes $N_{t b}$ & 3592 \\
\hline Material & Alloy $600 \mathrm{MA}$ \\
\hline Ultimate tensile strength (UTS) $S_{u}$ & $713 \mathrm{MPa}$ \\
\hline Yield strength (YS) $S_{y}$ & $362 \mathrm{MPa}$ \\
\hline
\end{tabular}




\subsection{The Spontaneous SGTR model}

Degradation of SG tubes largely impact NPPs operation. The most common form of degradation leading to failure is Stress Corrosion Cracking (SCC) that accounts for $60 \%$ to $80 \%$ of all tube defects requiring plugging. Fretting and pitting collectively account for another $15 \%$ to $20 \%$, whereas the remaining failures are due to mechanical damage, wastage, denting, and fatigue cracking (K.C Wade. 1995) (K. Chatterjee and M. Modarres, 2011). For this reason, without loss of generality, the spontaneous SGTR (with the associated tube cracking) is here considered to be only due to SCC (L. Cizelj \& B. Mavko. 1995) and we do not consider the management of leaked tubes but only the management of tube ruptures, for simplicity.

The tube cracking process can be divided into onset, formation and propagation of cracks inside the tube well. The crack onset (i.e., the generation of microcracks inside the tube bundle) is modelled relying on the actual data collected in the Zion Plant (see (R. Lewandowski et. al. 2016), for further details). Specifically, after 4 years (i.e., 2 refueling cycles), $31 \%$ of the tubes has been found cracked and $67 \%$ after 40 years (i.e. 20 cycles) (i.e., the onset probability decreases as the tube ages). Using the Maximum Likelihood Estimation (MLE) method (E. Zio. 2007), the data is confirmed to fit the Weibull distribution shown in Figure 3, with Probability Density Function (PDF)

$$
f(t)=\frac{b}{\lambda^{b}} t^{b-1} e^{\left(-\frac{t}{\lambda}\right)^{b}}
$$

where $b$ and $\lambda$ are found to be equal to $0.3654 y$ and 30.1609 , respectively.

Although various events of inappropriate tubes plugging have been recorded (see the NRC's LERSearch system, https://lersearch.inl.gov/LERSearchCriteria.aspx), in this work it is assumed that crack detection is perfect, neglecting any possibility of non-detection of cracks. The reason for this is that as the flaw depth approaches the $100 \%$ through-wall crack depth, the probability of non-detection drops to zero as shown in (Kupperman et al., 2009) and (R. Lewandowski et. al. 2016). 


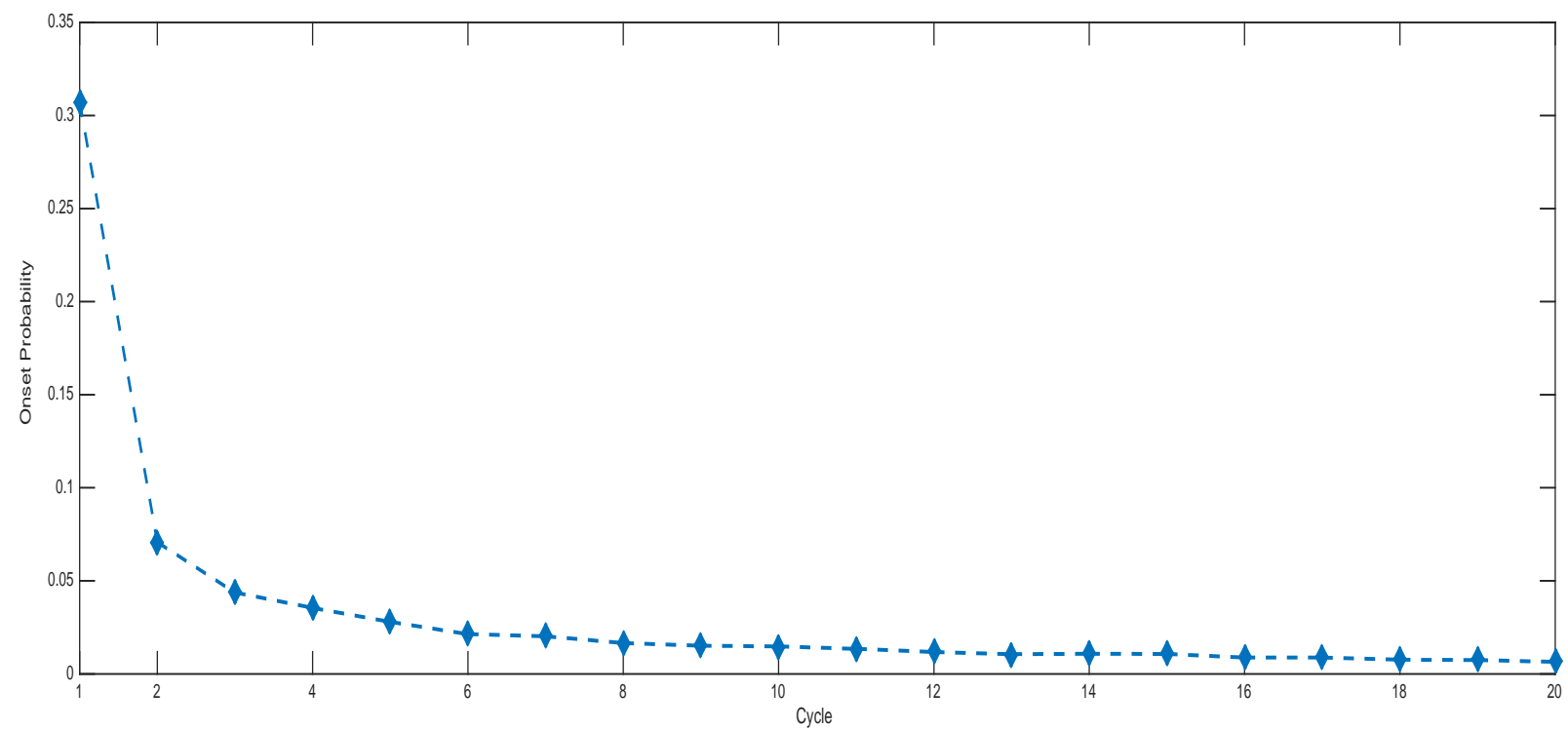

Figure 3. Probability of crack onset in a given cycle in a SG tube of a typical PWR (data taken from (R. Lewandowski et. al. 2016)).

The axial microcracks generated during the onset stage in the Alloy 600 MA tubes reach the critical crack length of $0.1 \mathrm{~mm}$ (i.e., the minimum length at which the crack starts propagating faster). This occurs in about 9.3 years (with standard deviation of 3.2 years) at the operating temperature of $330^{\circ} \mathrm{C}$ (L. Cizelj \& B. Mavko. 1995). The probability that a crack reaches the critical crack length of $0.1 \mathrm{~mm}$ is shown in Figure 4: this is the result of the convolution of the distribution of the crack onset probability of Figure 3 with the distribution of the time needed for the generated cracks to reach the length of 0.1 $\mathrm{mm}$, that, as said, obeys to a $\mathrm{N} \sim(9.3 \mathrm{y}, 3.2 \mathrm{y})$. In practice, even through the probability of crack onset is large during the infant life of the tubes, because of the time needed by the microcracks for reaching the length of $0.1 \mathrm{~mm}$, the critical length is (on average) reached in 5 cycles and, therefore, the corresponding distribution is shifted to the right. 


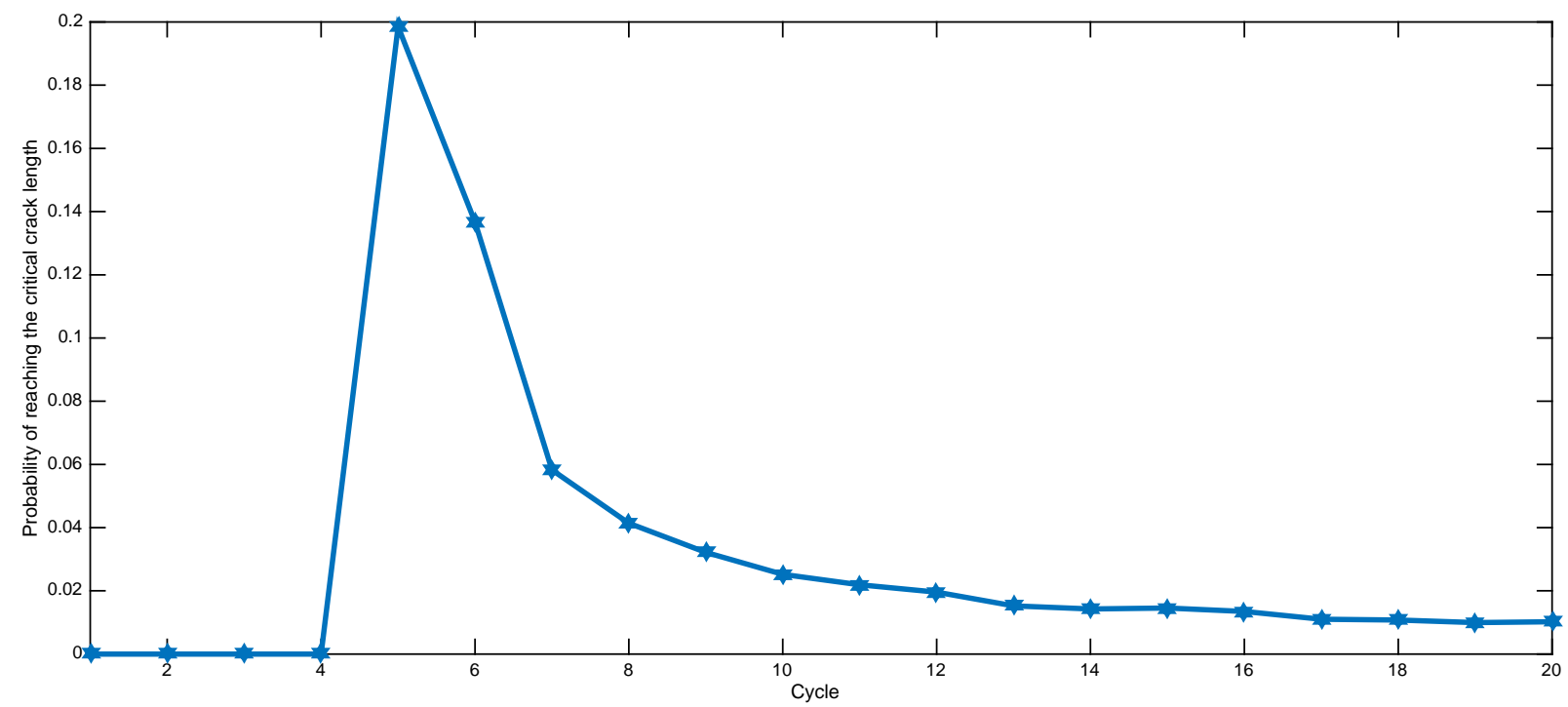

Figure 4. Probability that a crack reaches the critical length of $0.1 \mathrm{~mm}$, before starting to propagate up to tube rupture.

Finally, the propagation of cracks that reach the critical length of $0.1 \mathrm{~mm}$ is modeled with the Scott model (L. Cizelj \& B. Mavko. 1995), which is an empirical model that provides the crack length growth rate $\frac{d a}{d t}$ as a function of the stress intensity factor $K$

$$
\frac{d a}{d t}=\alpha \cdot\left(K-K_{t h}\right)^{\beta}
$$

where

$$
K=F \sigma \sqrt{\pi \frac{a}{2}}
$$

where $\alpha, \beta$ and $K_{t h}$ are constants that depend on the material (listed in Table II, for Alloy 600 MA when wet by water at $330^{\circ} \mathrm{C}(\mathrm{L}$. Cizelj \& B. Mavko. 1995)) and $a(0)=0.1 \mathrm{~mm}$ (i.e., the initial condition for crack length is assumed to be $0.1 \mathrm{~mm}$ ).

The stress crack tip $\sigma$ is proportional to a geometric factor $F$ (also given in Table II, for the case here considered), the pressure difference $\Delta P_{\text {nom }}$ between the inner and the outer sides of the SG tube, the outer diameter $d$ and the thickness of the tube $t$ (given in Table III). This allows calculating $\sigma$ 


$$
\sigma=\Delta \mathrm{P} \cdot \frac{\mathrm{d}}{2 \mathrm{t}}
$$

Table II. Crack growth parameters ((R. Lewandowski, 2013) and (L. Cizelj \& B. Mavko. 1995))

\begin{tabular}{|l|l|l|l|}
\hline Parameter & Minimum & Nominal & Maximum \\
\hline$\alpha$ & $2.5 \times 10^{-2}$ & $2.8 \times 10^{-2}$ & $3.1 \times 10^{-2}$ \\
\hline$K_{t h}(\mathrm{MPa} \sqrt{m})$ & 8 & 9 & 10 \\
\hline$\beta$ & 1.07 & 1.16 & 1.25 \\
\hline$F$ & - & 0.93 & - \\
\hline
\end{tabular}

Table III. Tubes parameters

\begin{tabular}{|l|l|l|}
\hline Parameter & Nominal Value & $\begin{array}{l}\text { Uncertainty } \\
\text { [uniform distribution] }\end{array}$ \\
\hline Outside diameter $d$ & $22.23 \mathrm{~mm}$ & $+/-0.5 \mathrm{~mm}$ \\
\hline Thickness $t$ & $1.27 \mathrm{~mm}$ & $+/-12.5 \%$ \\
\hline Nominal pressure difference $\Delta P_{\text {nom }}$ & $8.3 \mathrm{MPa}$ & $+/-1 \mathrm{MPa}$ \\
\hline
\end{tabular}

Following the NRC requirements (K.C Wade. 1995), the SG tube is plugged if the crack depth exceeds $40 \%$ of the nominal tube wall thickness $t$. Being $t=1.27 \mathrm{~mm}$, the plugging limit for the crack depth results to be equal to $0.51 \mathrm{~mm}$. Assuming a maximum depth-to-length ratio equal to $1 / 3$ ( $\mathrm{R}$. Lewandowski et. al. 2016), the SG tube has to be plugged when the crack length $a$ exceeds the value of $1.52 \mathrm{~mm}$. Plugging can be done only during refueling (i.e., each 2 years), because only during shutdown the SG tubes can be inspected using eddy current testing to determine the crack length. If, during the surveillance procedure, cracked tubes show crack lengths shorter than $1.52 \mathrm{~mm}$, plugging is not required and, therefore, cracks may continue to grow during the following cycle and propagate up to inducing a spontaneous SGTR.

The spontaneous rupture (and the following SGTR) occurs when the crack length $a$ exceeds the critical value $a_{c r}$ (plotted in Figure 5), that depends on the pressure difference $\Delta P$ in the tube wall (see Eq. (6)) (NUREG/CR-6664) (L. Cizelj \& B. Mavko. 1995)

$$
\Delta P=\frac{4 \sigma_{f} h}{m(2 d-h)}=\frac{p_{b}}{m}
$$


where $\sigma_{f}=0.6\left(S_{y}+S_{u}\right) \quad$ and $m=0.614+0.481 \lambda+0.386 e^{-1.25 \lambda} \quad$ (with $\lambda=\frac{1.82 a}{\sqrt{2 d-h}}$ and $p_{b}=$ $\left.\frac{4 \sigma h}{(2 d-t)}\right)$

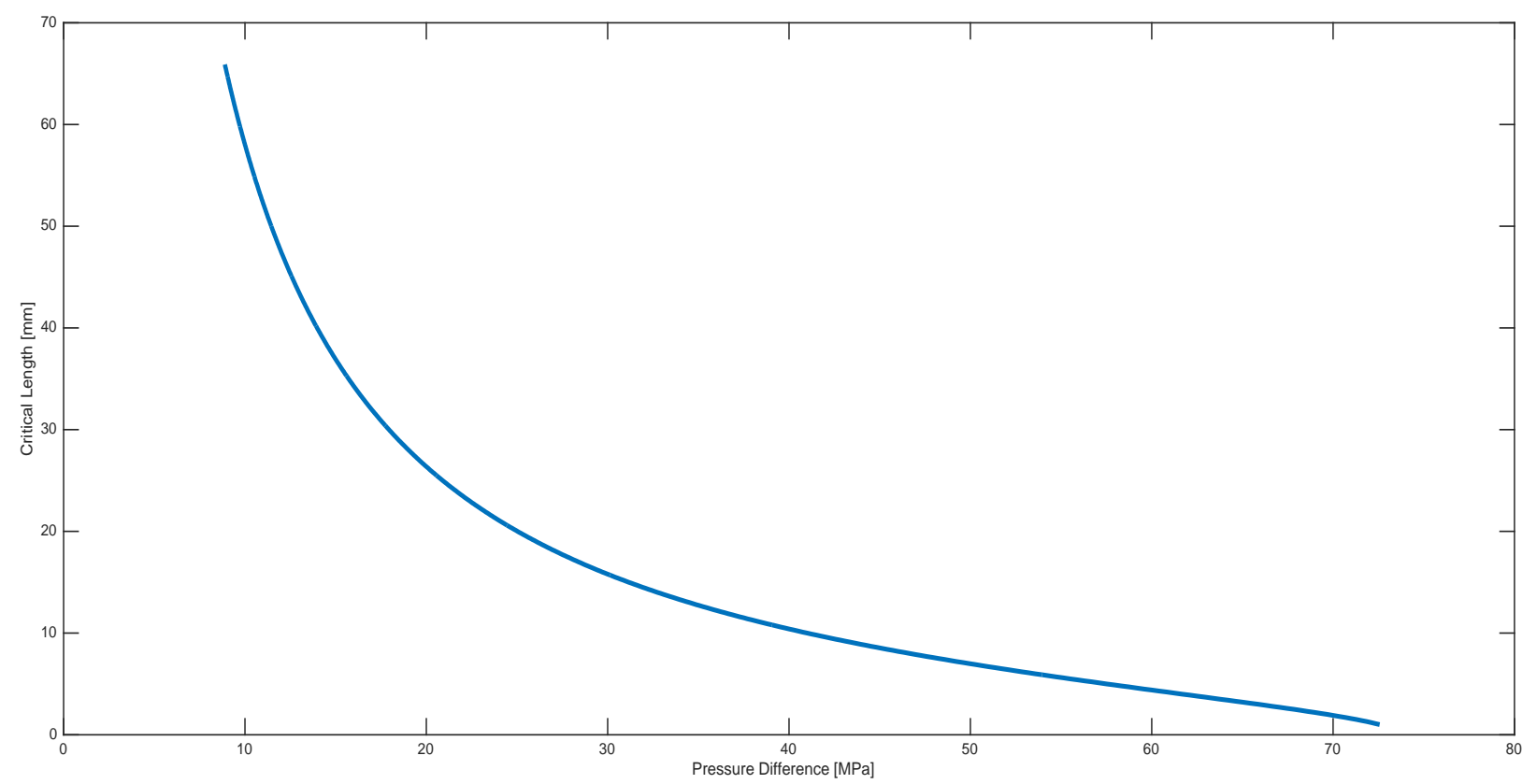

Figure 5. Critical crack length $a_{c r}$ in the SGTR, as a function of the pressure difference $\Delta P$.

\subsection{Estimation of SGTR frequency by LPSA}

If at inspection $a$ exceeds $1.52 \mathrm{~mm}$, the NRC requirement enforces plugging of the tubes (K.C Wade. 1995), causing a variation of the number of available SG tubes in operation $N_{t b}(t)$ and, therefore, a change in the plant configuration. Figures 6 and 7 show the fraction of tubes that are to be plugged at each cycle $t$, and the cumulative number of plugged tubes, respectively, that make the plant configuration changing over the NPP lifetime. It is worth stressing that the results obtained on the Zion NPP case may differ from those proposed by other authors addressing similar problems on different plants and cases (N. Johnson and J.A. Schroeder, 2016) (K.C Wade. 1995) (NUREG-1437). Again, the reason is that the LPSA and the CB-PSA approaches developed in this work are applied to the specific conditions of the Zion NPP, whereas the results of the previous works mentioned are obtained from a statistical analysis of data gathered from a population of similar NPPs. 


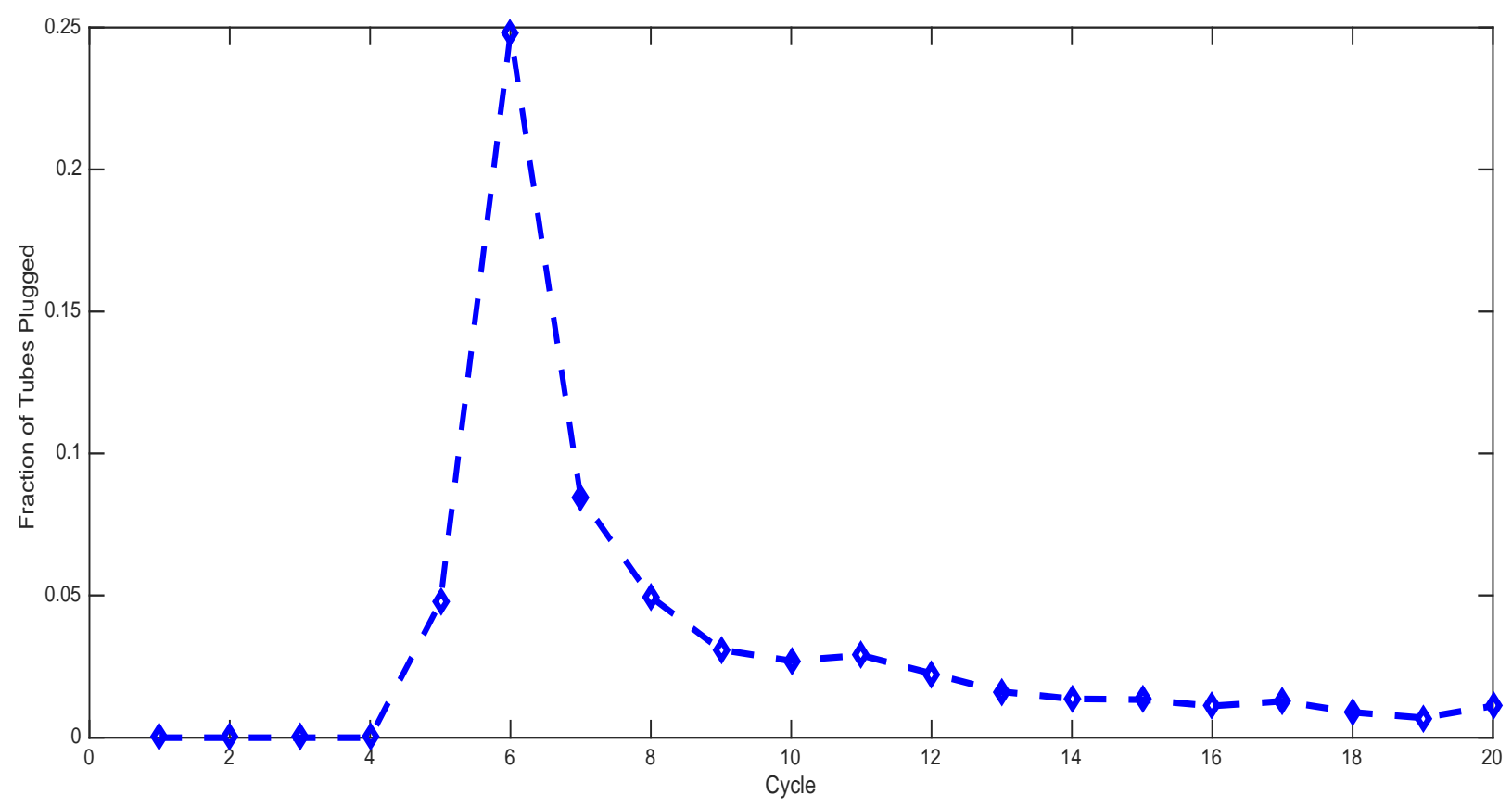

Figure 6. Fraction of tubes plugged in each cycle over the total number of tubes.

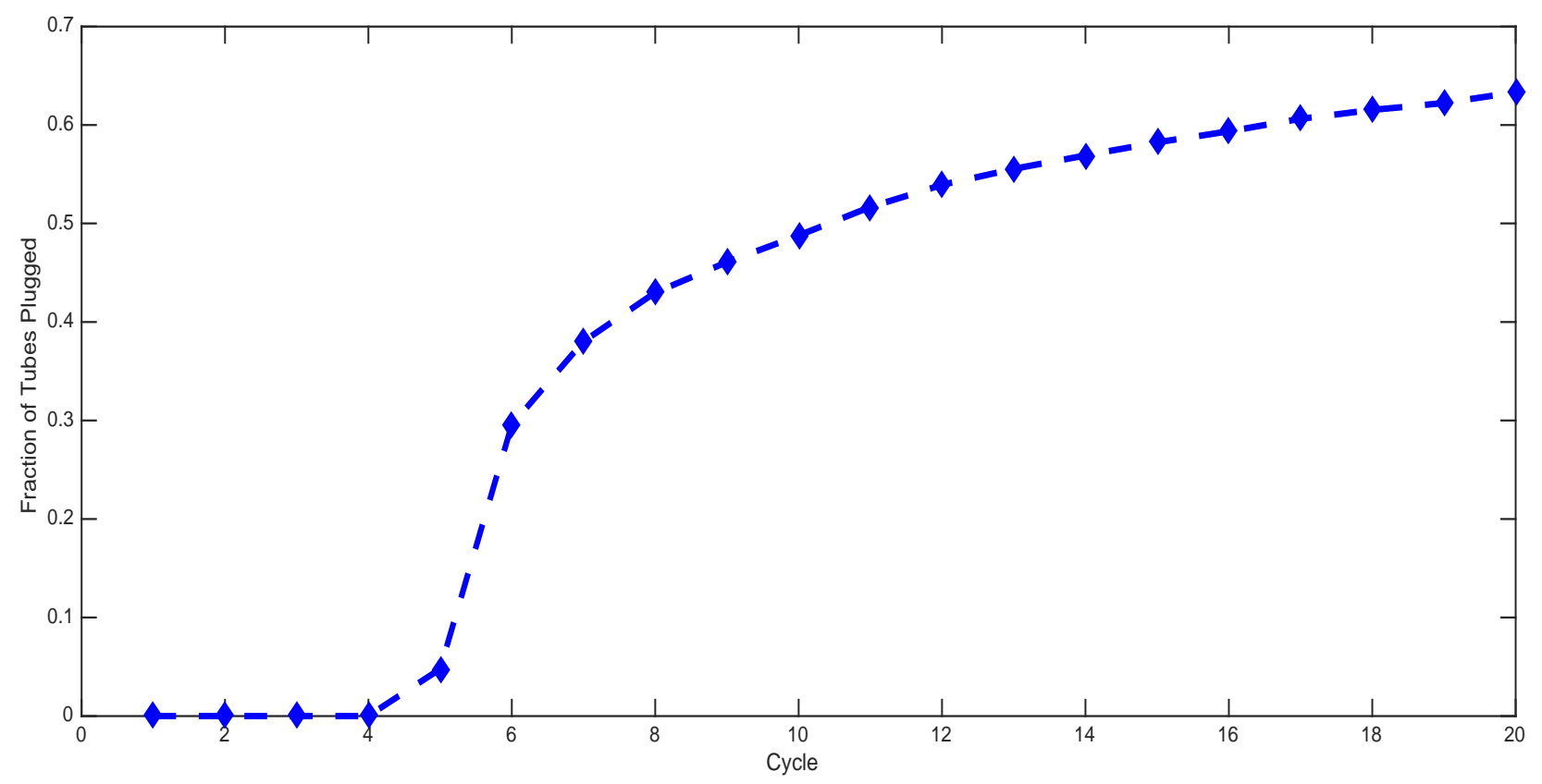

Figure 7. Fraction of the total number of tubes plugged at a given cycle over the total number of tubes.

The remaining tubes have to withstand an overpressure due to the fact that an increasing fraction of tubes is plugged over time, equal to 


$$
\Delta P=P_{\text {in }}\left(1+\frac{N_{\text {tb,plugged }}}{N_{t b}} \cdot \gamma\right)-P_{\text {out }, \text { nom }}
$$

Clearly, the larger the number $N_{t b, \text { plugged }}$ of plugged tubes the larger the $\Delta P$, as given in Eq. (7).

Figure 8 shows the pressure difference under nominal conditions $\Delta P_{\text {nom }}$ (dotted line) and the overpressure induced by the plugging procedure described in (K.C Wade. 1995), when $\gamma$ in Eq. (7) is assumed to be equal to 0.4 .

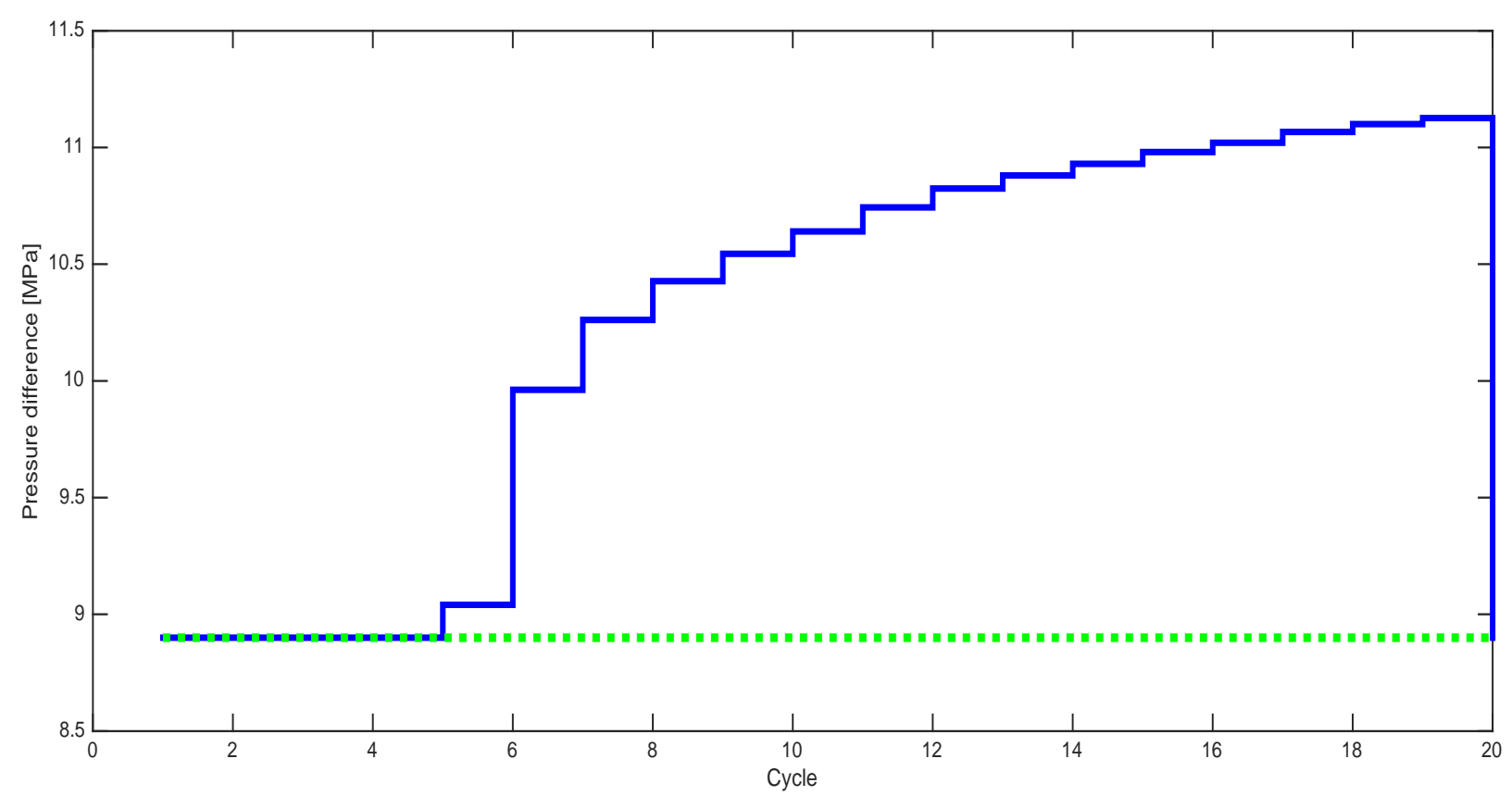

Figure 8. Pressure difference under nominal conditions (dotted line) and pressure difference induced by plugging (continuous line).

The expected tube rupture frequency between the $t$-th and the $(t+1)$-th inspection, has to be updated as in Eq. (8) below

$$
f_{T R}(t)=\frac{N(t)+1 / 2}{T \cdot N_{t b}(t)}
$$


where $N_{t b}(t)$ is the number of tubes that have not been already plugged at the $t$-th inspection, $N(t)$ is the number of tubes that will reach $a_{c r}$ (according to the propagation model of Eq. (3)) and originate a SGTR during the $t$-th cycle, $t=1,2, \ldots, T$. Assuming the $N_{t b}(t)$ tubes to be independent (i.e., neglecting any acceleration effect of tubes in the neighborhood of those plugged ones) the SGTR frequency in the $t$-th cycle results to be equal to:

$$
f_{S G T R}(t)=1-\prod_{N_{t b}(t)}\left(1-f_{T R}(t)\right)
$$

aa

Figure 9 shows the comparison between the SGTR frequency resulting from a conventional PSA (dotted line) and the SGTR frequency dynamically updated by the LPSA framework (continuous line), that accounts for the effects of the changes in the plant configuration. We notice:

i) a frequency value larger than that calculated with a conventional PSA throughout the SG lifetime, due to the large probability of a crack starting to propagate during the 5 -th and the 6 th cycles (see also Figure 4), combined with the overpressure induced by the plugging procedure (K.C Wade. 1995);

ii) a gradual reduction of frequency as long as the system life proceeds (even though the overpressure induced by the plugging procedure increases, as in Figure 8), due to the fact that most of the cracks are generated at early times, whilst the generation slows down at late times, because the onset and formation probabilities are lower (see Figure 4) at late times then at early times.

Similarly, Figure 10 shows the update of the CDF based on the LPSA. 


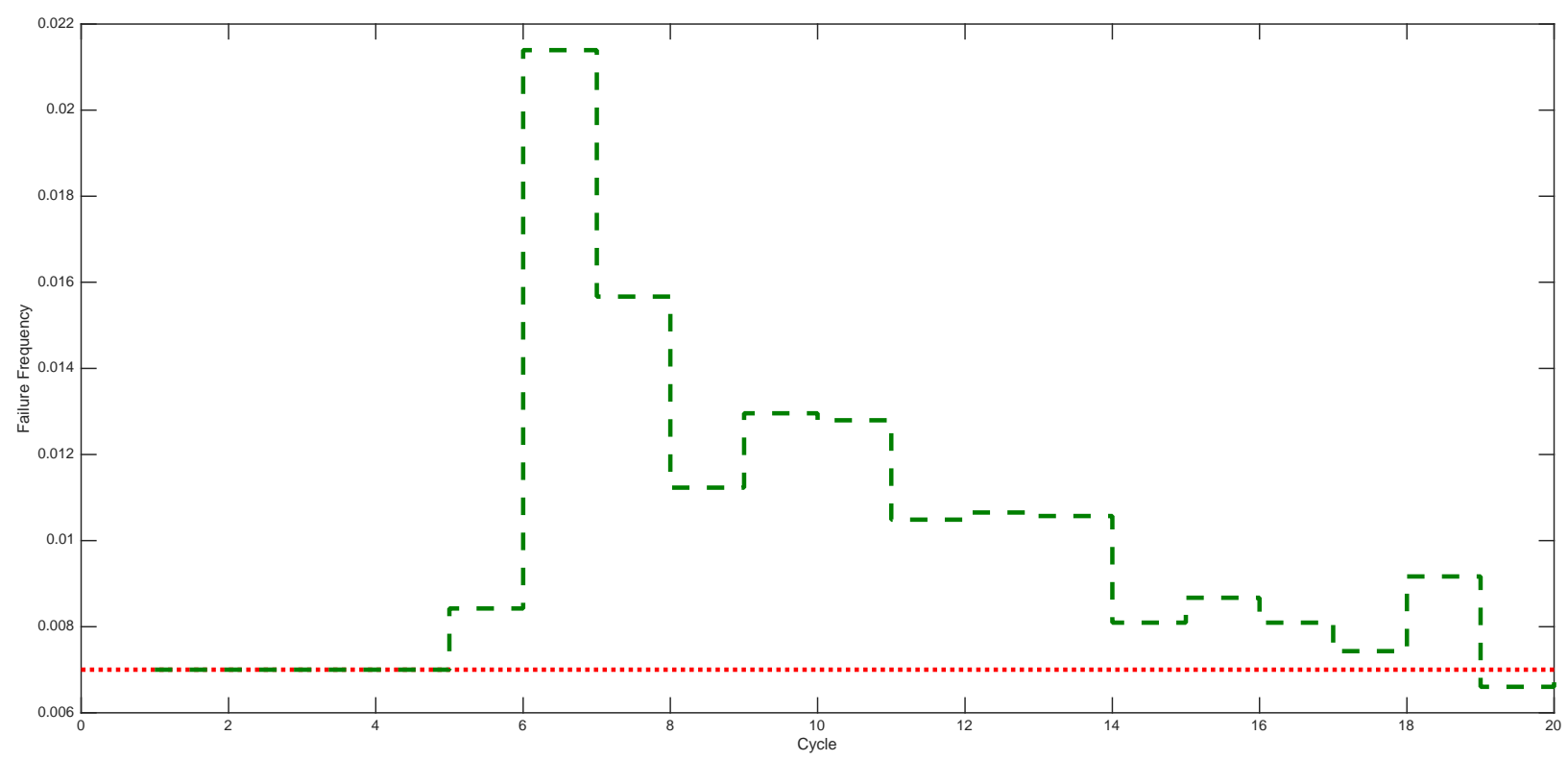

Figure 9. Comparison of the SGTR frequency during the 20 cycles of the SG lifetime between the conventional $f_{S G T R}$ of Eq. (1) (dotted line) and the LPSA $f_{S G T R}(t)$ (dashed line) that accounts for changes in the plant configuration.

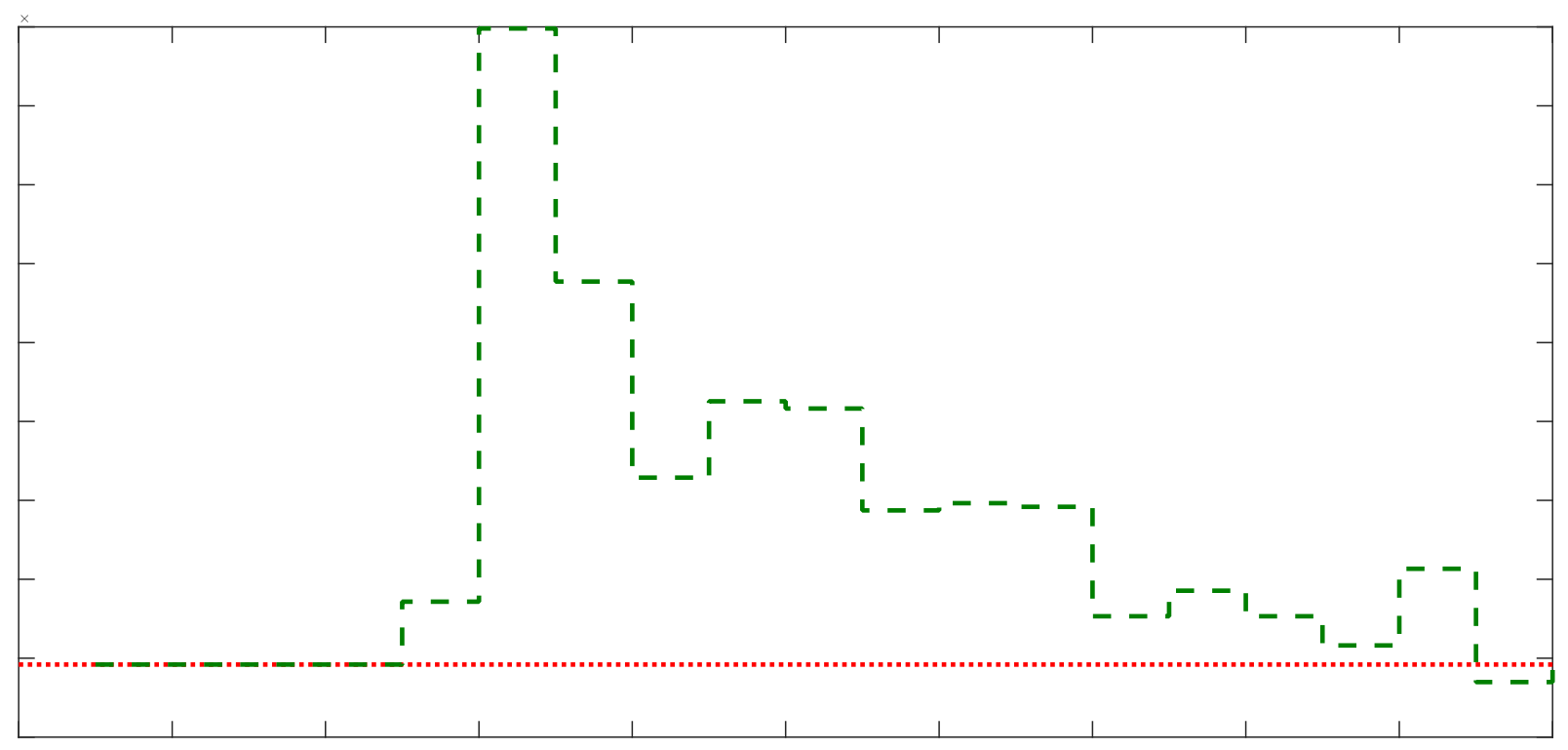

Figure 10. Comparison between the updated CDF resulting from the LPSA analysis (dashed line) and the CDF obtained with a conventional PSA framework (Figure 4).

It is important to notice that increasing the primary side pressure and, consequently, the pressure 
difference $\Delta P$ between the inner and the outer sides of the SGs tubes is not the only effect of plugging tubes. Alternative strategies for dealing with plugged tubes could have been adopted (such as derating the power of the SG, shortening operating cycle, etc.) (S. Newberry et al. 2000) (K.J. Karwoski 2009) (L. Obrutsky et. al. 2014). These strategies indeed would reduce the risk of SGTR while, instead, exposing the NPP to a possible increase of the operational costs and a reduction of revenues, due to a reduction of the load factor of the plant.

In order to show the potentiality of the proposed CB-PSA to limit and control the SGTR frequency, we hereafter assume to model the effect of plugged tubes only by increasing the primary side pressure, and, consequently, the $\Delta P$ that the remaining tubes have to withstand, with the possibility to preserving both safety and profitability, at the same time.

\section{Estimation of SGTR frequency in CB-PSA}

In this Section, we present the CB-PSA framework and the results it provides in the case study presented in the previous Section 2.

For the SGTR accident scenario, the novelty of CB-PSA with respect to LPSA is introduced in terms of the capability of updating, at each refueling cycle, the SGTR frequency according to the operative conditions that the NPP is expected to deal with during the following cycle. Other authors have proposed approaches for PSA updating using condition monitoring data (R. Lewandowski et. al. 2016) and (H. Kim et. al. 2015). These approaches are based on statistical analysis of data from a population of NPPs. Instead, the proposed framework combines the condition monitoring data with a physical model for degradation prediction of a system with its specific operative conditions. Indeed, as we have already seen, plugging does not uniquely favor safety, because this leads to a $\Delta P$ increase that, in turn, would increase the likelihood of the crack propagation. A trade-off must be found to avoid overconservativism (extra plugging) and under-estimation of crack propagation and tube rupture likelihood. The CB-PSA procedure that is here implemented is summarized as follows: 
1) At each inspection/refueling cycle $t$, simulate, for each tube, the onset, formation and propagation of the crack for the SG tube bundle (as described in Section 2.2) up to the following inspection/refueling cycle $t+1$. For simplicity, each tube is considered to be independent from the others (thus, its state is not influenced by its neighbor tubes degradation states), but due account is given to the tubes stochastic degradation that proceeds under the models parameters uncertainties, as listed in Tables II and III. In particular, since the tube bundle is affected by an evolving load condition profile (i.e., the NPP power demand $W$ ) along the 40 years (20 cycles) SG lifetime, and power affects the pressure difference $\Delta P$ (that strongly influences the tubes degradation mechanism), we consider the following Eq. (10) to hold for calculating the effective tube inner pressure $P_{\text {in }}$ under an effective $W$ that differs from $W_{\text {nom }}$

$$
P_{\text {in }}=P_{\text {in }, \text { nom }}\left(1+\frac{W}{W_{\text {nom }}}\right)
$$

Figure 11 shows, without loss of generality, an example of $W$ variation along the SG lifetime (hereafter assumed as reference load profile), whereas Figure 12 shows the resulting $\Delta P=P_{i n^{-}}$ $P_{\text {out,nom }}$ (continuous line), in comparison with the expected pressure difference under nominal conditions $\Delta P_{\text {nom }}=P_{\text {in,nom }}-P_{\text {out }, \text { nom }}$ (dotted line).

As done for the LPSA in Section 2.3, we assume that cracks that at inspection time $t$ exceed $1.52 \mathrm{~mm}$ are plugged according to the NRC requirement (K.C Wade. 1995). Considering the number of tubes that are to be plugged (as in Figures 6 and 7) and being the Eq. (7) the relationship that links the number of tubes plugged and the pressure difference that the remaining tubes will have to withstand (analogously to LPSA in Section 2.3), the resulting pressure difference $\beta$ can be calculated as the combination between the pressure difference resulting from the $W$ variations and the overpressure due to the plugging procedure.

Figure 13, continuous line, shows the overall condition-dependent pressure difference that a tube (which is never plugged) has to withstand throughout a SG lifetime, when affected by the reference load profile of Figure 11 and the plugging procedure described in (K.C Wade. 1995) is enforced. 


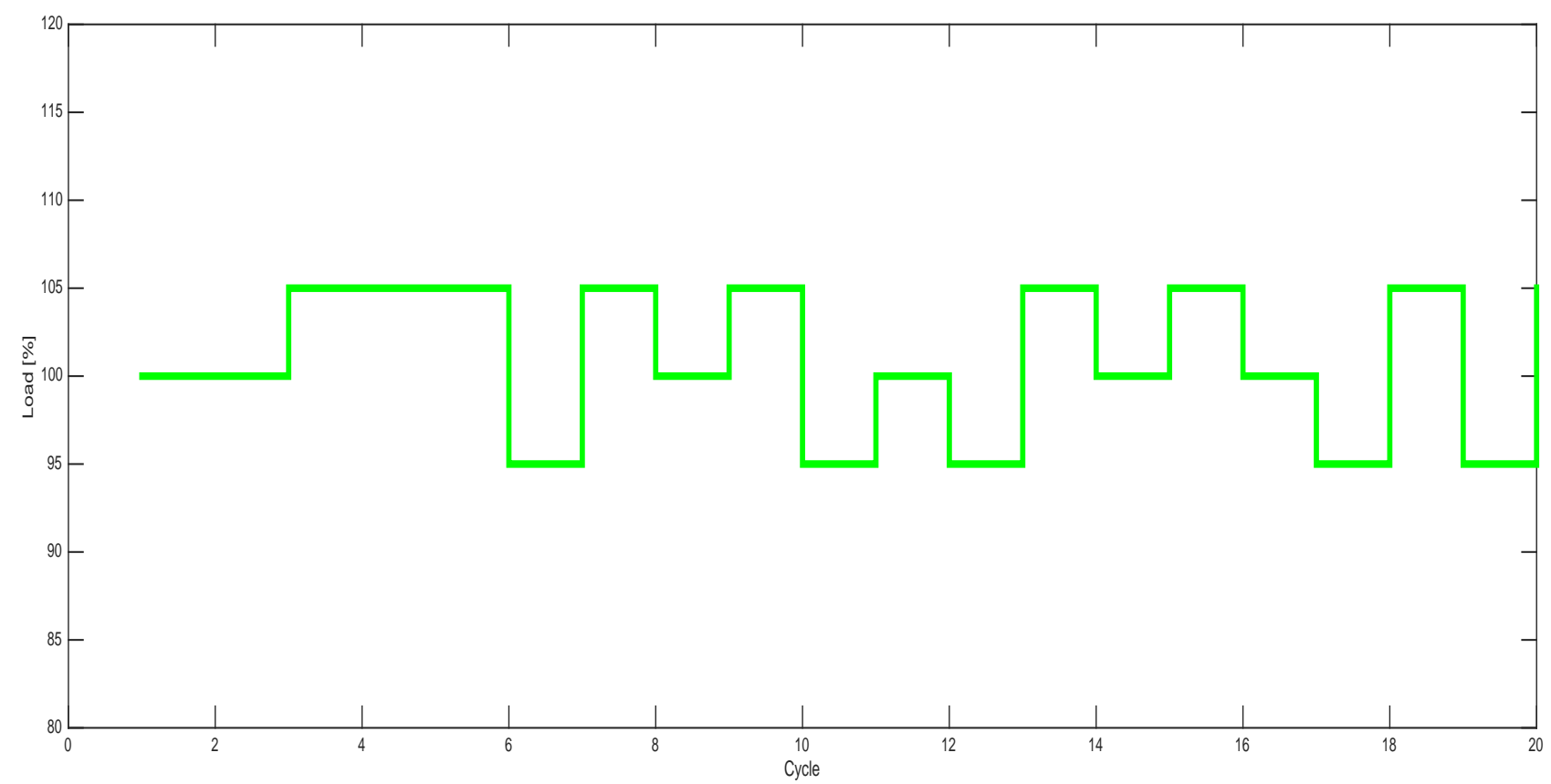

Figure 11. Reference load profile $W$ along the 40 years NPP lifetime.

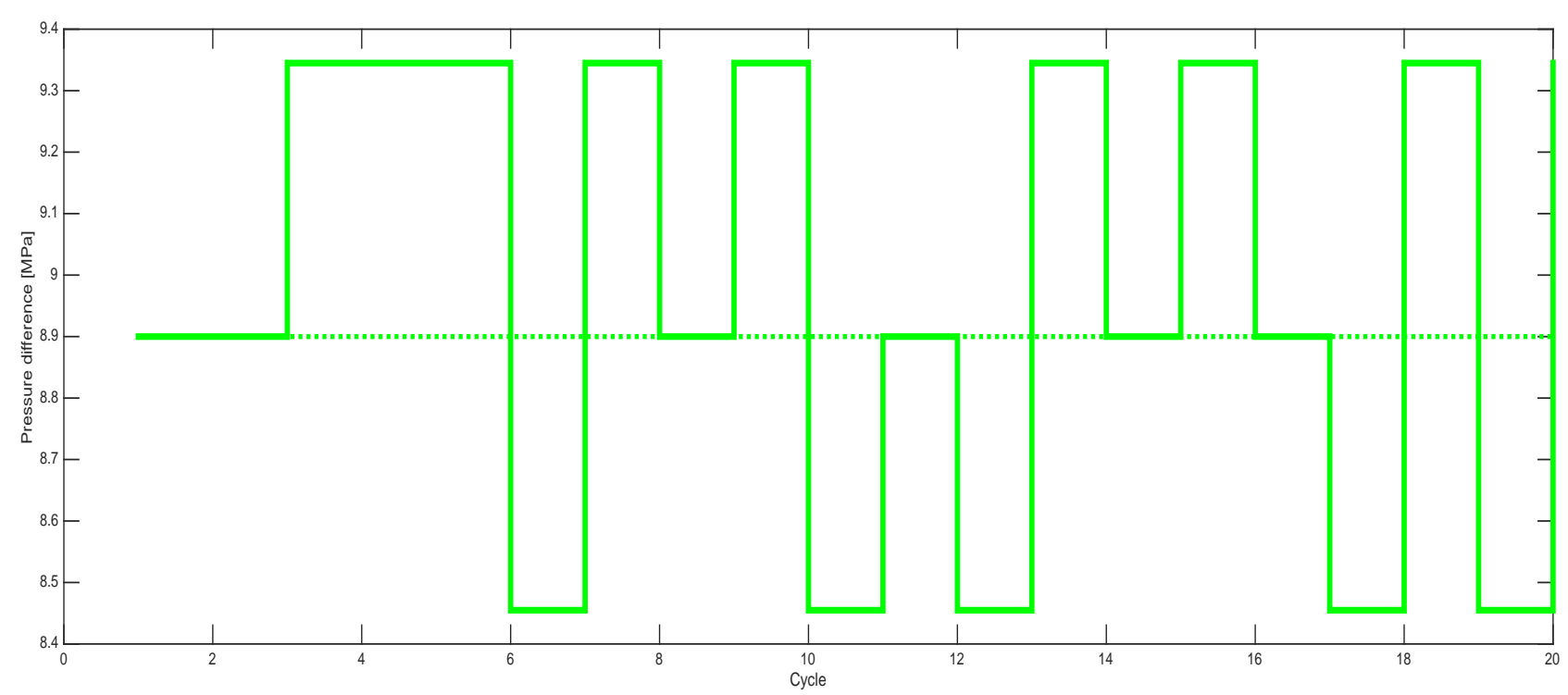

Figure 12. Pressure difference $\Delta P_{\text {nom }}$ under nominal conditions (dotted line) and pressure difference $\Delta P$ induced by the load variation (continuous line) during the 20 two-years cycles. 


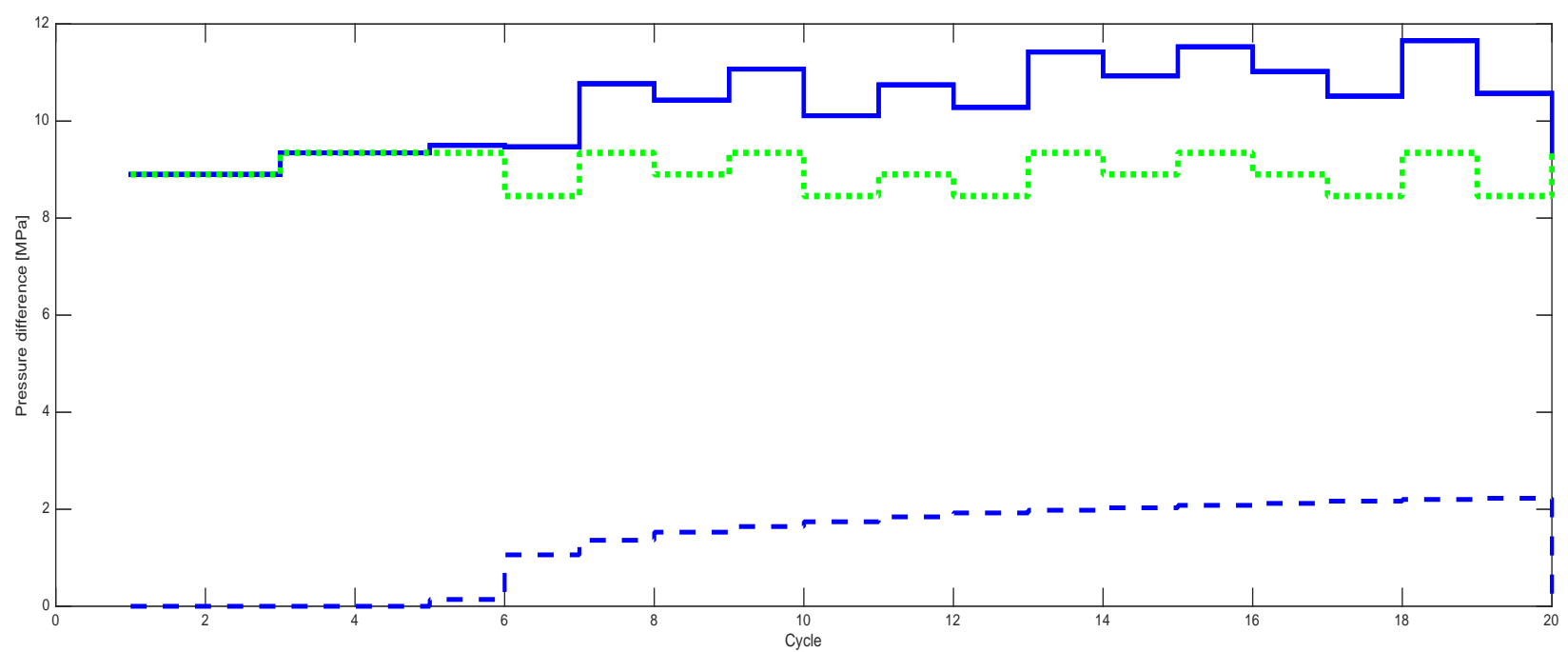

Figure 13. Pressure difference induced by the load variation (dotted line), pressure difference induced by the NRC plugging procedure (dashed line) and overall pressure difference that the tube has to withstand throughout the 20 two-years cycles of the SG lifetime (continuous line).

If any of the simulated stochastic crack evolutions (continuous line) is found to exceed the plugging threshold (dotted line in Figure 14) at the $t$-th inspection time, the NRC requirement is enforced and the tube plugged; otherwise, cracks are left growing up to the following inspection time, leaving the SG exposed to the risk of cracks exceeding the critical length $a_{c r}$ (dashed line). This dynamically changes, depending on the condition-dependent pressure difference of Figure 13 , as it occurs during the $7^{\text {th }}, 9^{\text {th }}, 15^{\text {th }}$ cycles (bold lines) in Figure 14 , for example. 


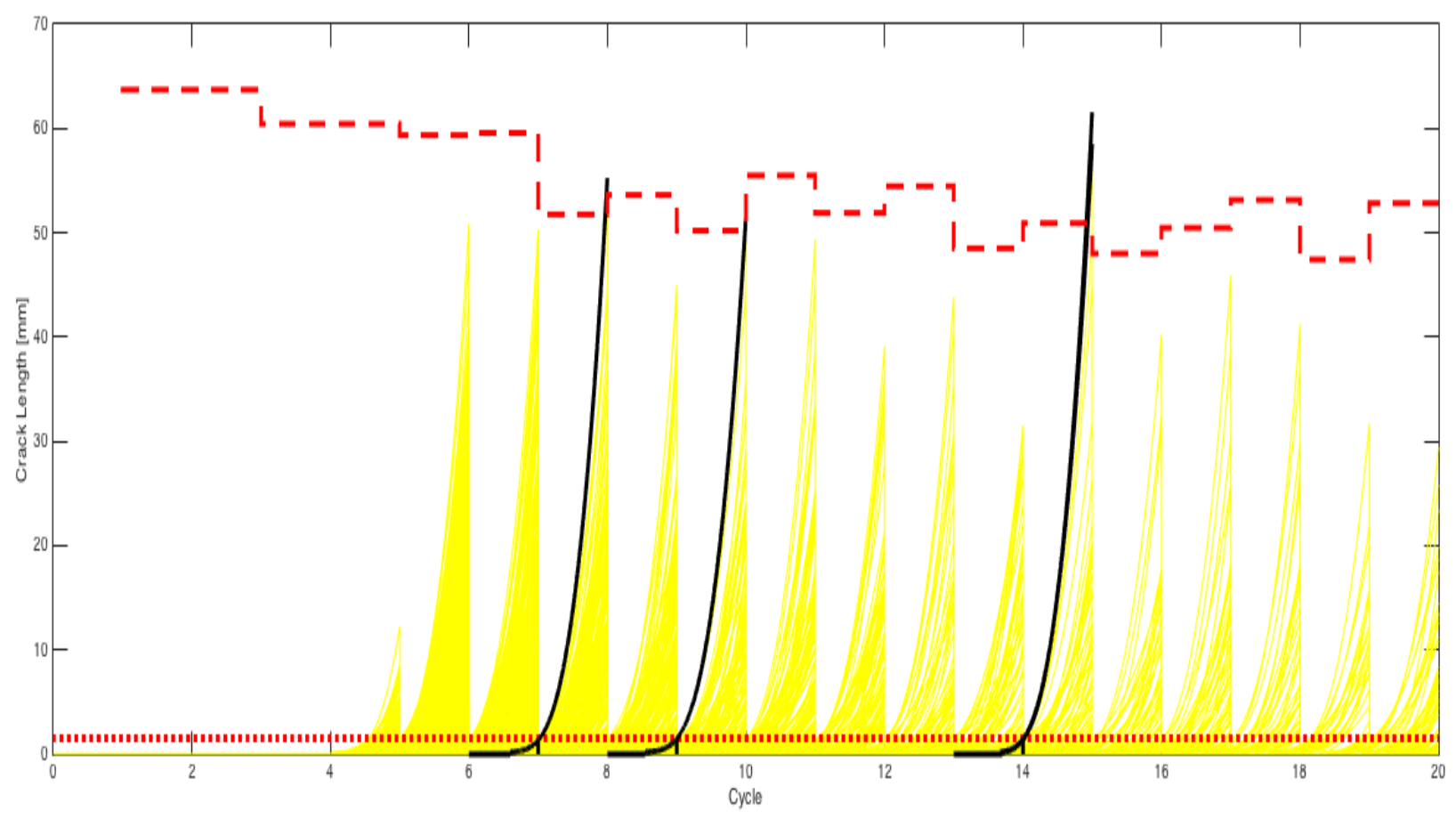

Fig. 14. Simulated cracks evolutions during the SG lifetime (continuous lines); plugging threshold (dotted line) and critical length $a_{c r}$ (dashed line), that dynamically changes due to the dependence on $W$ and $\Delta P$.

2) Calculate, by Eq. (9), the expected tube rupture frequency among the $t$-th and the $(t+1)$-th inspections, as for the LPSA. Then, assuming the $N_{t b}(t)$ tubes to be independent, the SGTR frequency among the $t$-th and the $(t+1)$-th inspection is equal to $f_{S G T R}(t)=1-\prod_{N_{t b}(t)}(1-$ $\left.f_{T R}(t)\right)$, as for the LPSA.

Figure 15 shows the tube ruptures that, according to simulation, are likely to occur (diamonds), the $f_{S G T R}(t)$ obtained in the CB-PSA framework (continuous line), the SGTR frequency computed in the LPSA framework (dashed line) and the SGTR frequency in a conventional PSA (dotted line). The $f_{S G T R}(t)$ value in the CB-PSA framework is larger than the conventional $f_{S G T R}$ during cycles in which some tubes ruptures occur, whereas it is lower when no ruptures occur. This shows that CB-PSA realistically accounts for the observed evidence and it is neither over-conservative nor under-conservative. One can also notice that the larger the value of $\Delta P$ (see also Figure 13), like during the $7^{\text {th }}, 9^{\text {th }}, 15^{\text {th }}$ cycles, the larger the value of the CB-PSA $f_{S G T R}(t)$, with respect to the LPSA $f_{S G T R}(t)$. 


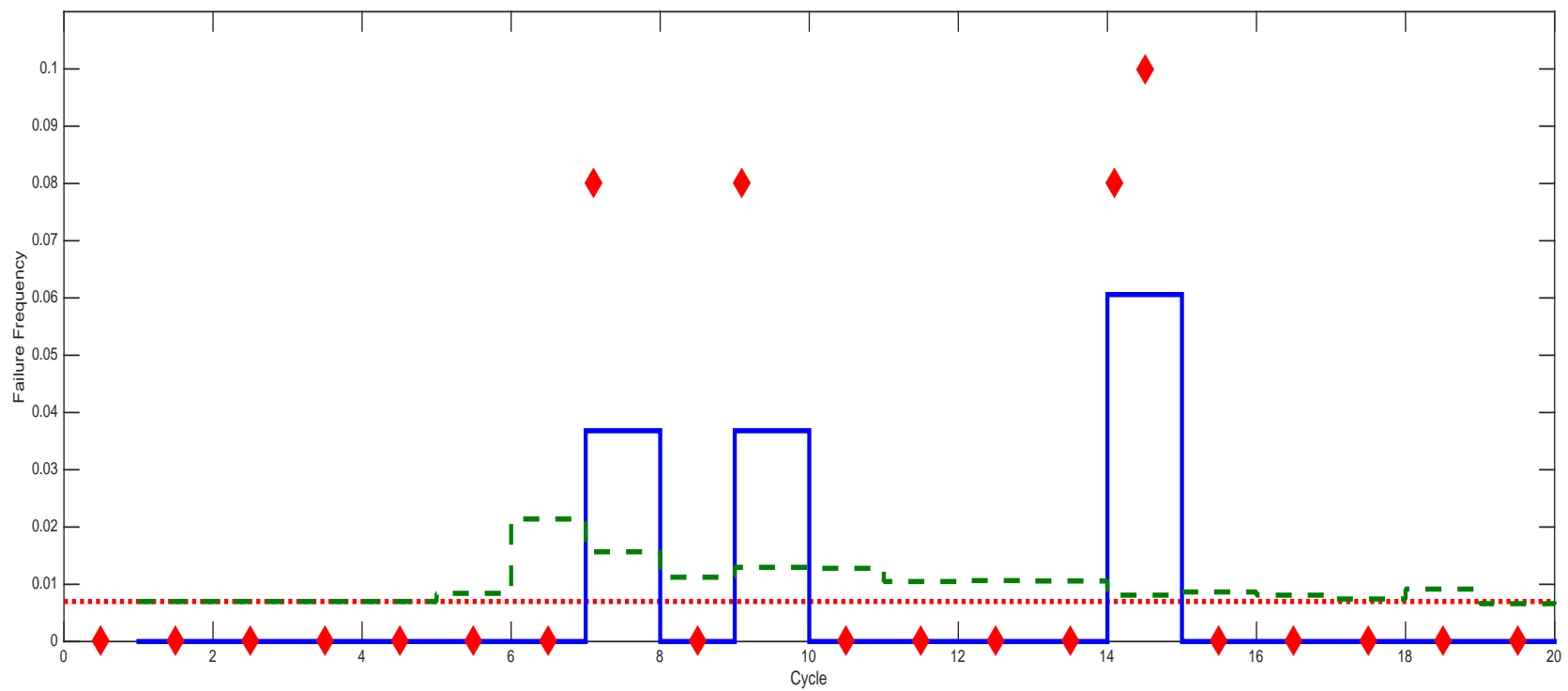

Figure 15. SGTR frequency resulting from conventional PSA (dotted line), LPSA (dashed line), CB-PSA (continuous line) that accounts for the effects of $W$ and $\Delta P$ variations on the tubes, and for the number of tube ruptures collected during each cycle (diamonds).

Figure 16 shows that the CDF varies along $t$ because of the CB-PSA estimation of $f_{S G T R}(t)$. The comparison with the result provided by the conventional PSA and the LPSA shows their inability of accounting for the effects of the real system conditions.

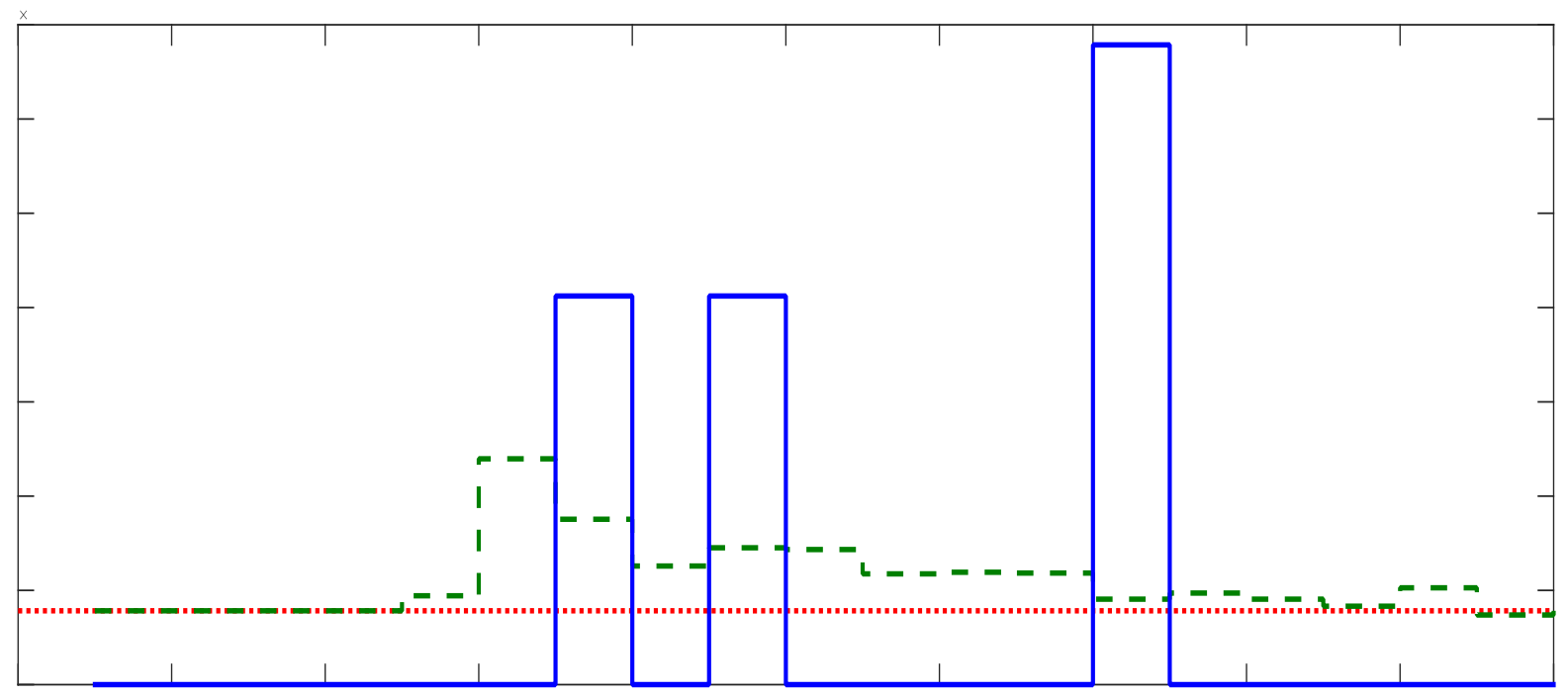


Figure 16. Comparison between the updated CDF resulting from CB-PSA (continuous line), the CDF resulting from LPSA framework (dashed line) and the CDF obtained by conventional PSA (dotted line).

\subsection{Optimization of the plugging strategy to control the escalation of potential SGTR IEs}

The expected $f_{S G T R}(t)$ result from CB-PSA can be used for informing at each $t$-th inspection time the decision on whether to plug (or not) cracked tubes. We propose an optimization of the plugging strategy to control the occurrences of potential SGTR IEs, counterbalancing overpressure due to plugging and probability of additional tube failures.

The procedure of analysis goes as follows (and is operationalized in the pseudo code of Figure 18)

I. At each cycle $t$, simulate for each one of the $N_{t b}$ tubes of the SG bundle, the onset, formation and propagation as described in 1), accounting for the same dependences on $W$ and $\Delta P$.

II. At the end of each cycle $t$, during the inspection, collect the measurements of the crack lengths, that are not plugged, even if found with $a$ exceeding $1.52 \mathrm{~mm}$. Then, for each crack, simulate $N_{s}$ alternative stochastic evolutions of the crack during the next $t+1$ cycle, relying on the tubes stochastic degradation as described in Section 2.2, and with the model parameters uncertainties listed in Tables II and III, to evaluate the probability that the crack length exceeds the critical length $a_{c r}$ during such cycle. Without loss of generality, Figure 17 shows an example of $N_{s}$ simulations (continuous lines) originated by the same crack initiated during a generic $t$-th cycle (dashed-dotted line); the probability distribution of the crack length reached at the end of the $t+1$ cycle can be calculated, as well as the probability of exceeding the critical length $a_{c r}$ that causes the SGTR (dashed line).

III. Compute, for each tube, the 99-th-percentile of the probability distribution of the crack length that is reached at the end of the $t+1$ cycle and plug the tube if this value exceeds the critical length $a_{c r}$ that could originate the SGTR under the expected $W$ and $\Delta P$ conditions of the cycle under analysis. Then, compute the pressure difference that the remaining tubes will have to 
withstand during the $(t+1)$-th cycle, by Eq. (7) and Eq. (10), and, again, simulate the $t+1$ cycle of life of each of the $N_{t b}(t+1)$ available tubes as in II, under the updated operational conditions. It seems important to specify that the $99^{\text {th }}$-percentile considered in the work has been arbitrarily selected because in practice a risk-averse option is typically adopted, rather than a risk-prone one, to reduce at minimum the probability of failures: the lower the percentile, the larger the risk endorsed by the decision-maker; vice versa, the larger the percentile, the lower the probability of SGTR.

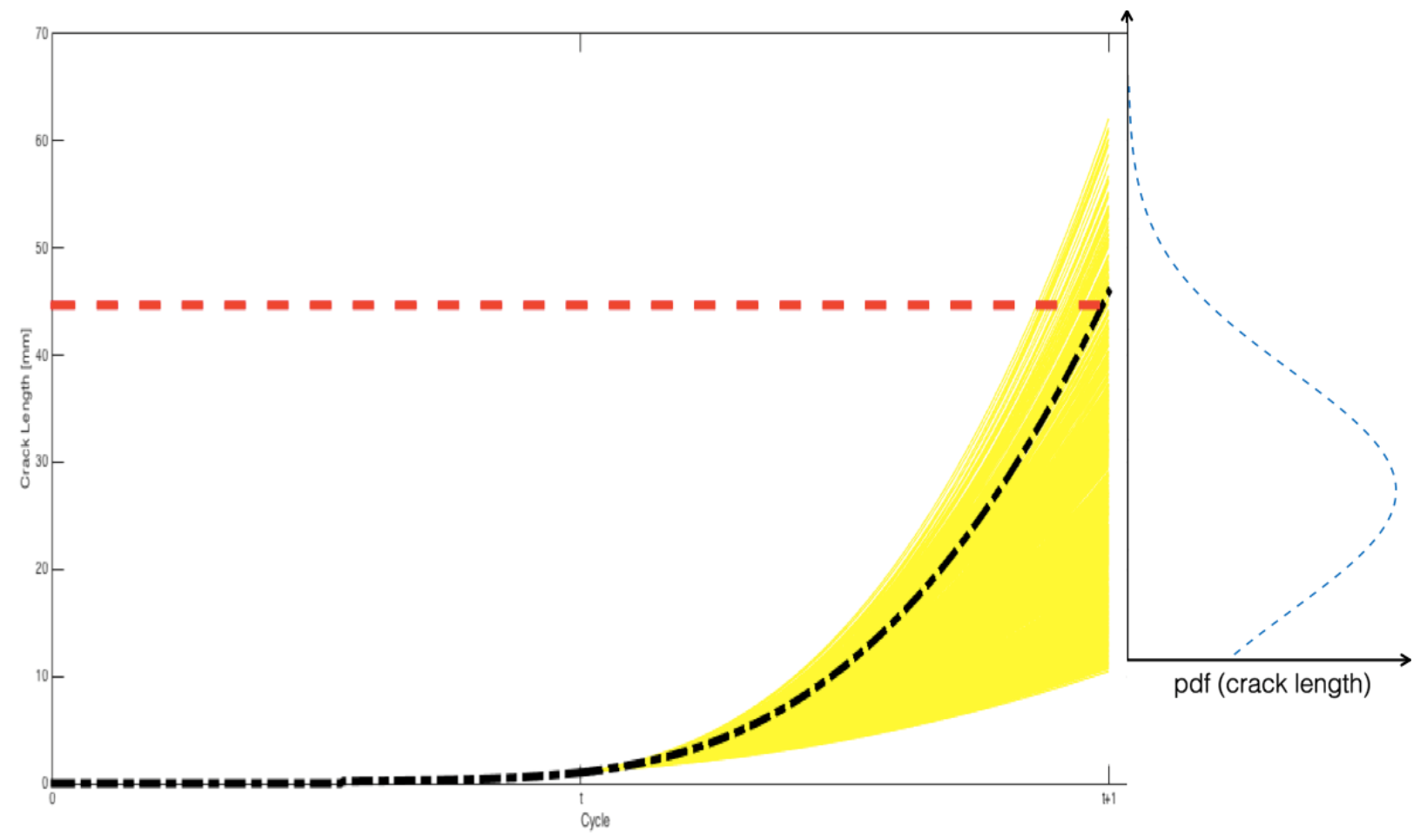

Figure 17. Simulated crack during a generic $t+1$ cycle (shadowed area) and associated probability distribution for the crack length at the end of the cycle (dashed line on the right), compared with the critical length acr that causes the SGTR (dashed horizontal line).

IV. Based on III, calculate the expected tube rupture frequency $\hat{f}_{T R}(t)$ between the $t$-th and $(t+1)$-th inspections (as in Eq. (11))

$$
\hat{f}_{T R}(t)=\frac{N(t)+1 / 2}{T \cdot N_{t b}(t)}
$$

The expected SGTR frequency $\hat{f}_{S G T R}(t+1)$ is, then, calculated as in Eq. (12) 


$$
\hat{f}_{S G T R}(t)=1-\prod_{N_{t b}(t)}\left(1-\hat{f}_{T R}(t)\right)
$$

V. At cycle $t+1$, proceed with step I above until $T$ is reached, by setting the initial crack length equal to that found at the $t$-th inspection.

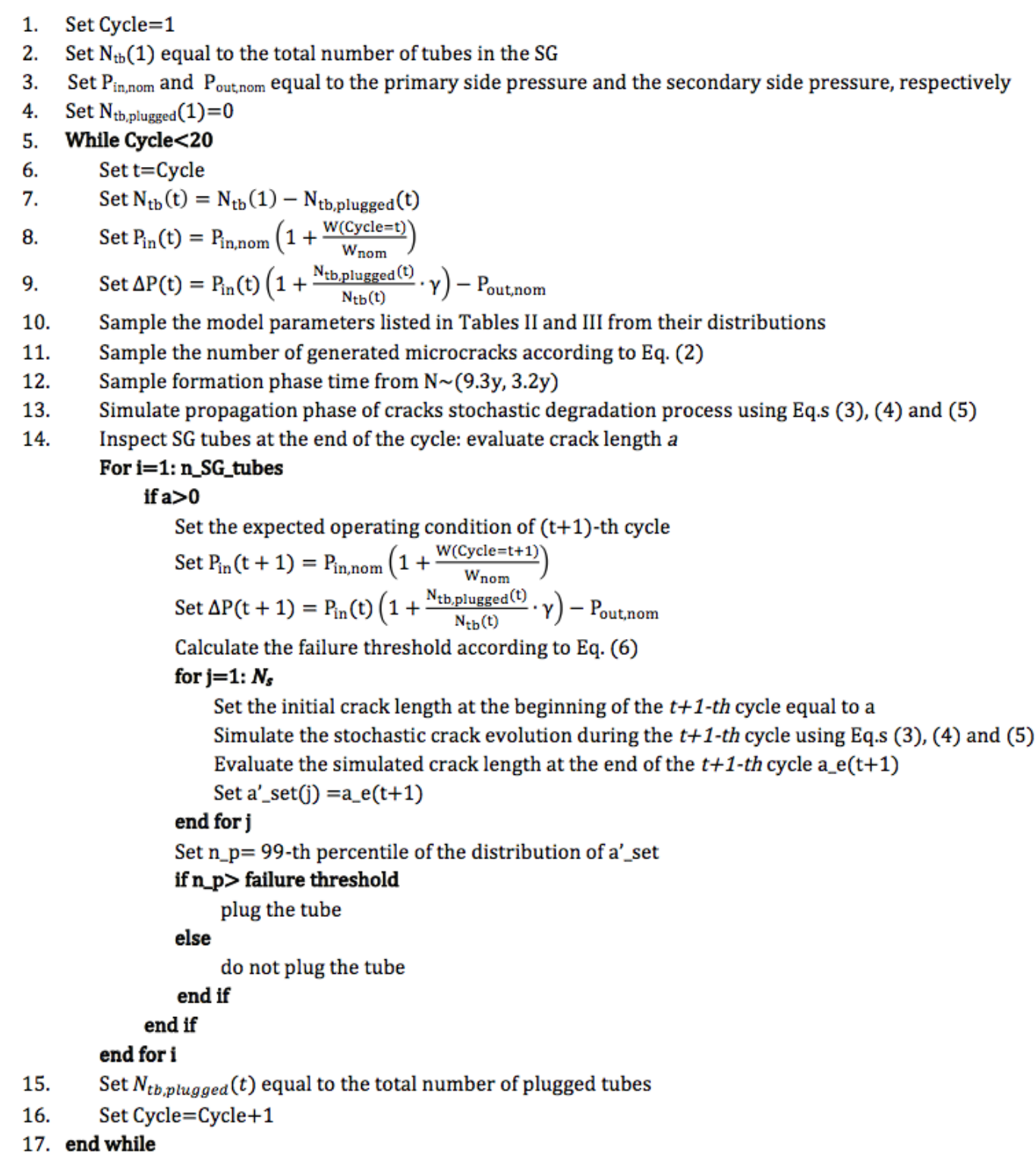

Figure 18. Pseudo-code of the optimization of the plugging strategy.

Figure 19 shows (diamonds) the tube ruptures occurring (at each cycle), the $\hat{f}_{S G T R}(t)$ obtained with the plugging optimization procedure (dashed line) and the SGTR frequency resulting from a traditional PSA (continuous line). Comparing this result with the results in Figure 20, which show the tube ruptures occurring (diamonds) and the $\hat{f}_{S G T R}(t)$ obtained if the NRC requirement were enforced (dashed line), it 
is worth highlighting the reduction both of the tube ruptures (from several to zero) and of the predicted SGTR frequency, thanks to the proposed optimization of the plugging procedure.

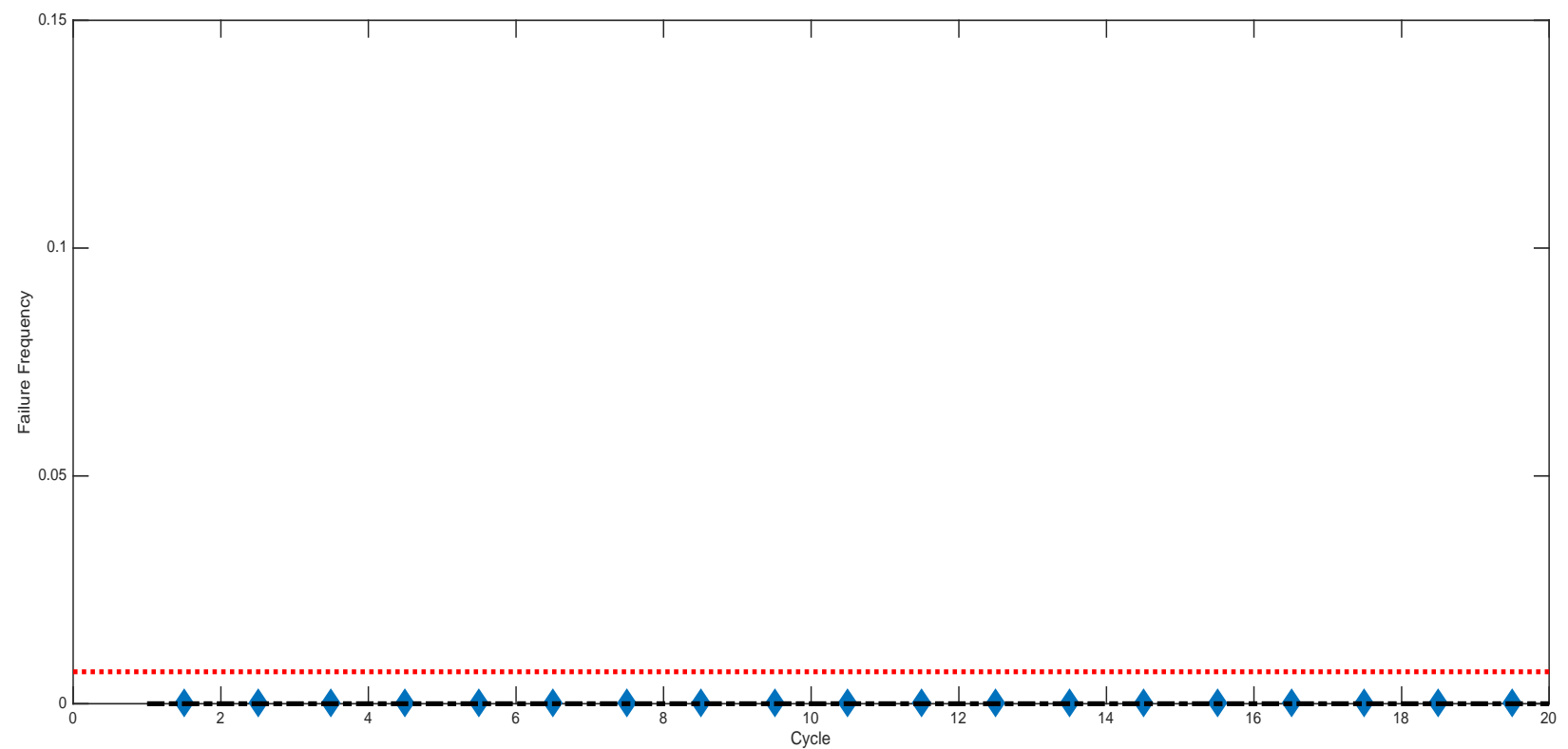

Figure 19. Comparison between the $\widehat{f}_{S G T R}(t)$ resulting from the proposed optimization of the plugging strategy (dashed-dotted line) and the SGTR frequency obtained from a traditional PSA (dotted line). Diamonds represent the number of tube ruptures collected during each cycle. 


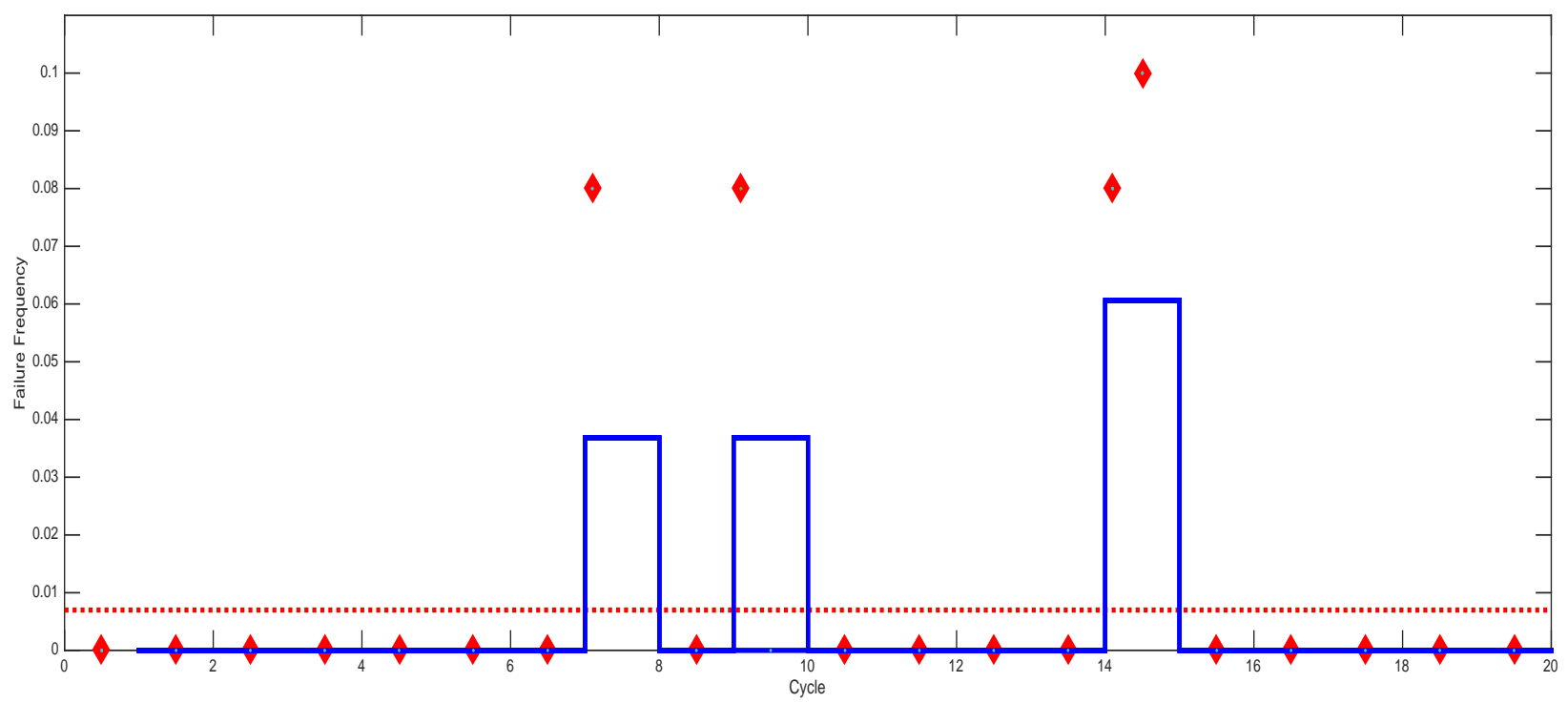

Figure 20. Comparison between the $\widehat{f}_{S G T R}(t)$ resulting if the NRC requirement were enforced (continuous line) and the SGTR frequency obtained from a traditional PSA (dotted line). Diamonds represent the number of tube ruptures collected during each cycle.

As for CB-PSA, the dynamically update of the predicted SGTR frequency (Figure 20) allows for a dynamic calculation of the associated predicted CDF (Figure 22). We can notice that, despite of the variation of the operating conditions induced by the plugging strategy, the CDF resulting from this procedure is null and the expected failures are zero. 


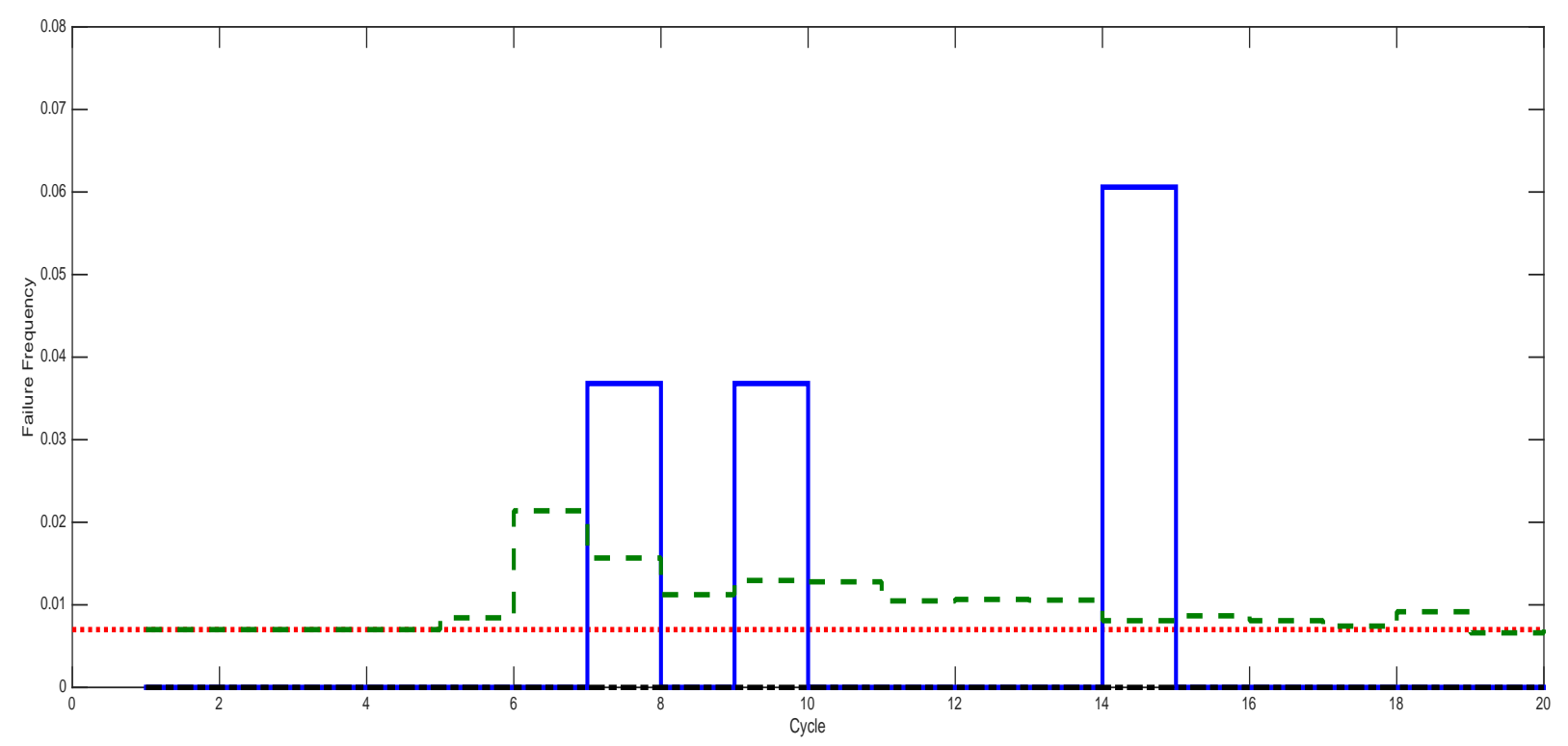

Figure 21. Comparison between the CDF resulting from conventional PSA (dotted line), the CDF obtained from LPSA (dashed line), the CDF resulting from the optimization of the plugging procedure (dashed dotted line) and the CDF resulting if the NRC requirement were enforced (continuous line).

\section{Conclusions}

CB-PSA extends and advances LPSA, currently used in NPPs. While LPSA provides an estimation of the NPP risk given the current plant configuration (i.e., the number of operating tubes, in the case study considered), CB-PSA allows incorporating also the components monitored conditions and its results can be used to define activities (i.e., plugging, in the case study considered) for controlling the escalation of possible accident scenarios.

In this work, the spontaneous SGTR accident scenario is considered as the case study for the demonstration of CB-PSA. A physics-based model for the onset, formation and propagation of spontaneous cracks in the SG is tailored on cracks observations collected by inspection at successive inspection cycles and, then, used to update the probability of the SGTR IE. The degradation mechanisms that affect the SG tubes, which cause the SGTR, are duly accounted using conditionmonitoring data, physical and organizational changes. The CDF is, then, correspondingly updated, 
reflecting the most insightful and comprehensive knowledge regarding the components and system state of degradation.

The comparison of the results obtained in the case study considered by conventional PSA, LPSA and CB-PSA exemplifies the original contribution of the work, that can be summarized in the ability of the CB-PSA to account for the monitored conditions of the components, augmenting the knowledge utilized to provide the PSA risk measures estimates: the empirical distributions (based on field failure data) utilized by conventional PSA and LPSA are replaced by condition-based distributions obtained by the integration of physics-based knowledge and monitoring data, providing a less conservative and more realistic risk-informed approach to safety assessment, with respect to PSA and L-PSA.

As last remark, it seems important to emphasize that, beside the assumptions made for computational reasons (e.g., only SCC is taken as degradation mechanism of SG tubes, detection is ideally considered perfect, tubes are assumed to be independent, strategy for dealing with plugged tubes is by increasing primary side pressure) other factors should be investigated, such as NDE inspection cost and exposure effects of workers, to fully acknowledge the benefit of the proposed optimization approach as decisiongrade method/tool.

\section{References}

T. Aldemir. 2013. "A survey of dynamic methodologies for probabilistic safety assessment of nuclear power plant", Annals of Nuclear Energy, vol. 52, February 2013, Pages 113-124

K. Chatterjee and M. Modarres, "A Probabilistic Physics of Failure Approach to Prediction of Steam Generator Tube Rupture Frequency", ANS PSA 2011 International Topical Meeting on Probabilistic Safety Assessment and Analysis, Wilmington, NC, March 13-17, 2011.

L. Cizelj \& B. Mavko. 1995. "Propagation of stress corrosion cracks in steam generator tubes", International Journal of Pressure Vessels and Piping 63(1), 1995, Pages 35-43.

J.W. Hines, D. Garvey, J. Garvey \& R. Seibert. 2008. "Technical Review istepiof On-line Monitoring Techniques for Performance Assessment”, NUREG/CR-6895, vol. 3-Limiting Case Studies, U.S. Nuclear Regulatory Commission, Washington D.C.

[IAEA-TECDOC-737, 1994], "Advances in reliability analysis and probabilistic safety assessment for nuclear power reactors” IAEA, IAEA-TECDOC-737, Vienna.

[IAEA-TECDOC-1106, 1999], "Living probabilistic safety assessment (LPSA)", IAEA, IAEATECDOC-1106, Austria.

IAEA. 2008 "PSA, Living PSA and Risk Monitoring, Key Differences and Conversion”, International Atomic Energy Agency, Vienna (Austria), Div. of Technical Co-operation Programmes, p. 161172; Workshop on PSA applications, Sofia (Bulgaria), 7-11. 
[IAEA, International Atomic Energy Agency, 2013], Advanced Surveillance, Diagnostic and Prognostic Techniques in Monitoring Structures, Systems and Components in Nuclear Power, International Atomic Energy Agency SERIES No. NP-T-3.14, Vienna.

G. Johanson \& J. Holmberg. 1994 "Safety Evaluation by Living Probabilistic Safety Assessment. Swedish Nuclear Power Inspectorate", TemaNord 1994:614, Copenhagen.

N. Johnson and J.A. Schroeder, "Initiating Event Rates at U.S. Nuclear Power Plants: 1988-2015," INL/EXT-16-39534, Idaho National Laboratory, May 2016.

Y. Jun, Y. Ming, H. Yoshikawa \& Y. Fangqing. 2014. "Development of a risk monitoring system for nuclear power plants based on GO-FLOW methodology", Nuclear Engineering and Design vol. 278, 2014, p. 255-267.

H. Kim, S.H. Lee, J.K. Park, H Kim, Y.S. Chang \& G. Heo. 2015. "Reliability Data Update Using Condition Monitoring And Prognostics In Probabilistic Safety Assessment", Nuclear Engineering and Technology vol. 47, Issue 2, Pages 204-221.

D.S. Kupperman, et al., 2009. "Eddy Current Reliability Results from the Steam Generator Mock-up Analysis Round-Robin,” NUREG/CR-6791. U.S. Nuclear Regulatory Commission.

R. Lewandowski. 2013. "Incorporation of Corrosion Mechanisms into a State-dependent Probabilistic Risk Assessment", The Ohio State University, Ohio.

R. Lewandowski, R. Denning, T. Aldemir \& J. Zhang. 2016. "Implementation of condition-dependent probabilistic risk assessment using surveillance data on passive components", Annals of Nuclear Energy 87, 690 - 760.

R. Nakai \&Y. Kani. 1991. "A Living PSA system LIPSAS for an LMFBR", International symposium on the use of probabilistic safety assessment for operational safety, Vienna (Austria); 3-7 Jun 1991.

[NEA/CSNI/R(99)15, 1999 ], "State of Living PSA and Future Development", NEA, NEA/CSNI/R, France.

[NUREG/CR-6365 INEL-95/0383, 1996], “Steam Generator Tube Failures”, U.S National Regulatory Commission, NUREG/CR-6365, Washington D.C.

[NUREG/CR-5750, 1998], "Rates of Initiating Events at U.S. Nulcear Power Plants: 1987e1995", U.S National Regulatory Commission, NUREG/CR-5750, Washington D.C.

K.C Wade. 1995. "Steam generator degradation and its impact on continued operation of pressurized water reactors in the United States". Energy Information Administration/Electric Power Monthly, NRC, August, 1995:

L. Obrutsky, J. Renaud, and R. Lakhan, "Overview of Steam Generator Tube- Inspection Technology," CINDE Journal, V. 35(2), 2014.

E. Plischke, E. Borgonovo \& CL. Smith. 2013. "Global Sensitivity Measures from Given Data", European Journal of Operational Research, vol. 226, Issue 3, 1 May 2013, Pages 536-550.

S. Poghosyan \& A. Amirjanyan. 2015 "Risk-informed Prioirtization of Modernization Activities Using Ageing PSA", Nuclear Engineering and Technology, vol 47, Issue 2, March 2015, Pages 204-21.

H. Prasad, G. \& Vinod, S. Rao. 2015. "Risk management of NPPs using risk monitors", International Journal of System Assurance Engineering and Management, vol. 6, Issue 2, June 2015, Pages 191197.

P. Rahuhalli, A. Veeramany, C. A. Bonebrake, W. J. Ivans Jr., G. A. Coles \& E. H. Hirt. 2016 "Evaluation of Enhanced Risk Monitors for Use on Advanced Reactors", 2016 24th International Conference on Nuclear Engineering, Charlotte, North Carolina, USA.

P.V. Varde \& M.G. Pecht. 2015. "Role of prognostics in support of integrated risk-based engineering in nuclear power plant safety", Nuclear Engineering and Technology, vol. 47, Issue 2, March 2015, Pages 204-211.

E. Zio. 2007. "An Introduction to the Basics of Reliability and Risk Analysis", World Scientific Publishing Co. Re. Ltd.,sépi: 2007.

E. Zio. 2009. "Computational Methods for Reliability and Risk Analysis", World Scientific Publishing Co. Re. Ltd., 2009.

E. Zio. 2016. "Some Challenges and Opportunities in Reliability Engineering", IEEE Transactions on Reliability, vol. 65, Issue: 4, Dec. 2016.

M. Zubair, Z. Zhang \& S.U. Khan. 2011.SEP."A methodology for Living Probabilistic Safety Assessment (LPSA) based on Advanced Control Room Operator Support System (ACROSS)", Annals of 
Nuclear Energy vol. 38, Issue 6, June 2011, Pages 1351-1355. 